The Astrophysical Journal, 224:724-744, 1978 September 15

(C) 1978. The American Astronomical Society. All rights reserved. Printed in U.S.A.

\title{
VIRIAL PROPERTIES OF GROUPS OF GALAXIES
}

\author{
HERBERT J. ROOD \\ Department of Astronomy and Astrophysics, Michigan State University \\ AND \\ JOHN R. DICKEL \\ University of Illinois Observatory and Sterrewacht Leiden \\ Received 1977 October 24; accepted 1978 March 20
}

\begin{abstract}
Modern techniques and data are used to derive virial parameters for numerous well-known groups of galaxies. Virial mass-to-light ratios are typically 40-120 solar units. The groups are gravitationally bound because $(a)$ their crossing times are smaller than a Hubble time, and $(b)$ the composite frequency distribution of their radial velocities is "approximately" Gaussian. A correlation is observed between the virial mass-to-light ratio and the virial velocity dispersion. Contributions to this correlation by projection and quasi-equilibrium effects, radial velocity uncertainties, and uncertainties in galactic mass are evaluated and found to be too small to explain the correlation. The average surface density of galaxies in groups appears to be independent of distance from the center out to a mean limiting radius.
\end{abstract}

Subject heading: galaxies: clusters of

\section{INTRODUCTION}

Since the early studies of the dynamics of groups of galaxies (see, e.g., Neyman, Page, and Scott 1961; Limber 1961; Karachentsev 1966; Burbidge and Sargent 1971; Rood, Rothman, and Turnrose 1970), there have been several improvements in analytical techniques and basic data: $(a)$ The various types of uncertainties in the determination of the mass of a group by application of the virial theorem were enumerated by Aarseth and Saslaw (1972), who examined some of them. (b) Rigorous virial relations which include corrections for random errors in radial velocity measurements were derived by Materne (1974). (c) Determinations of velocity dispersions within the cores of individual early-type galaxies and other evidence (Morton and Chevalier 1972, 1973; Wilson 1975; Faber and Jackson 1976; Faber et al. 1977; Williams 1977; Sargent et al. 1977) indicated that the average mass-to-light ratio of elliptical and S0 galaxies is about the same as the average mass-tolight ratio of spiral galaxies, not several times larger as had been believed previously. $(d)$ The quality and quantity of systemic velocities of galaxies has increased considerably, primarily from measurements of the $21 \mathrm{~cm}$ hydrogen line. (e) Turner and Gott (1976a) compiled a new catalog of groups constructed by an automatic procedure from a strict density-contrast criterion, $(f)$ Geller and Peebles (1973) created a powerful statistical method to derive the average mass-to-light ratio of groups which automatically discards spurious systemic velocities and does not require decisions about whether any particular galaxy is a member of any particular group.

The present study applies the above developments to the determination of mass-to-light ratios, crossing times, and other dynamical properties of groups. The goal is to provide a set of fundamentally correct results which will contribute toward our understanding of the nature of groups and reduce some of the current confusion about them. The study is comprehensive enough to reflect our knowledge of the virial properties of groups at the present stage of research, that is, prior to the completion of several extensive and homogeneous surveys of radial velocities of galaxies which are now in progress.

\section{CALCULATION OF VIRIAL PARAMETERS}

The classical way to identify a group of galaxies is primarily to notice a similarity in systemic velocities among galaxies located in a region of significantly larger than average surface density. Perhaps the most definitive of the classical groups are listed by Sandage and Tammann (1975). Additional groups are listed by de Vaucouleurs (1975). Still more classically identified groups in the southern hemisphere are listed by Sandage (1975). These southern groups tend to be richer in early-type galaxies, fainter, and more distant than the other groups, which are mainly composed of members of the Shapley-Ames (1932) cataloggalaxies brighter than 13th magnitude. We will designate this entire sample of groups spanning the whole sky as the STV groups.

The 63 STV groups with three or more known galactic redshifts are listed in Table 1 . Obvious foreground and background galaxies were filtered from the groups on the basis of their radial velocities. This was easy to do without ambiguity except for groups $\mathrm{deV} 7$ and deV 17. (The mass-to-light ratios listed in Table 1 are those obtained when the doubtful group 
TABLE 1

Virial Properties of STV Groups

\begin{tabular}{|c|c|c|c|c|c|c|c|c|c|c|c|c|c|c|c|}
\hline Group & $\begin{array}{l}\text { Gro } \\
\text { ST }\end{array}$ & $\begin{array}{l}\text { oup } \\
\text { deV }\end{array}$ & $\mathbf{N}$ & $\begin{array}{l}\mathrm{d}_{\mathrm{cm}} \\
\mathrm{Mpc}\end{array}$ & $\begin{array}{l}<\mathrm{v}\rangle \\
\mathrm{km} \mathrm{s}\end{array}$ & $\begin{array}{l}\langle\text { r }> \\
\text { Mpc }\end{array}$ & ${ }_{10}^{t}{ }^{10}$ yrs & $\mathbf{f}_{\mathbf{s}}$ & $\mathrm{V} / \mathrm{s}^{-1}$ & $\begin{array}{l}\text { R } \\
\text { Mpc }\end{array}$ & $\begin{array}{l}{ }^{t} \mathrm{VT} \\
10^{10} \mathrm{yrs}\end{array}$ & ${ }_{10^{10}}^{L_{L O}}$ & ${ }_{10^{10}}^{\mathrm{L}_{\mathrm{T}}}$ & $\frac{\mathrm{M}_{\mathrm{VT}}}{\mathrm{L}_{\mathrm{T}}}$ & $\frac{\sigma\left(v^{2}\right)}{v^{2}}$ \\
\hline $\begin{array}{l}\mathrm{Scl} \\
\mathrm{M} 81 \\
\mathrm{cVnI} \\
\text { N5128 } \\
\text { M51 }\end{array}$ & $\begin{array}{l}x \\
x \\
x \\
x \\
x\end{array}$ & $\begin{array}{l}1 \\
2 \\
3 \\
4\end{array}$ & $\begin{array}{r}7 \\
10 \\
10 \\
6 \\
3\end{array}$ & $\begin{array}{c}4.43 \\
4.21 \\
7.61 \\
6.64 \\
12.0\end{array}$ & $\begin{array}{r}285 \\
144 \\
154 \\
105 \\
66\end{array}$ & $\begin{array}{r}.80 \\
.63 \\
1.26 \\
1.34 \\
.86\end{array}$ & $\begin{array}{r}.3 \\
.4 \\
.8 \\
1.2 \\
1.3\end{array}$ & $\begin{array}{r}1.00 \\
1.00 \\
.99 \\
.63 \\
1.00\end{array}$ & $\begin{array}{r}195 \\
161 \\
172 \\
47 \\
49\end{array}$ & $\begin{array}{r}3.09 \\
1.11 \\
4.21 \\
5.04 \\
.71\end{array}$ & $\begin{array}{r}1.5 \\
.7 \\
2.4 \\
10.4 \\
1.4\end{array}$ & $\begin{array}{c}12.4 \\
6.99 \\
12.9 \\
23.2 \\
14.5\end{array}$ & $\begin{array}{l}12.7 \\
7.08 \\
13.0 \\
25.2 \\
24.4\end{array}$ & $\begin{array}{r}216 \\
94 \\
223 \\
10 \\
2\end{array}$ & $\begin{array}{l}.05 \\
.06 \\
.05 \\
.81 \\
.43\end{array}$ \\
\hline $\begin{array}{l}\text { M101 } \\
\text { N2841 } \\
\text { N1023 } \\
\text { N2997 } \\
\text { Leo }\end{array}$ & $\begin{array}{l}x \\
x \\
x\end{array}$ & $\begin{array}{l}6 \\
7 \\
8 \\
9+11\end{array}$ & $\begin{array}{r}6 \\
6 \\
5 \\
5 \\
19\end{array}$ & $\begin{array}{l}8.01 \\
13.0 \\
14.7 \\
16.0 \\
15.2\end{array}$ & $\begin{array}{r}106 \\
181 \\
86 \\
945 \\
328\end{array}$ & $\begin{array}{l}.36 \\
1.69 \\
1.03 \\
2.59 \\
1.45\end{array}$ & $\begin{array}{r}.3 \\
.9 \\
1.2 \\
.3 \\
.4\end{array}$ & $\begin{array}{r}1.00 \\
.87 \\
.71 \\
.82 \\
.75\end{array}$ & $\begin{array}{r}51 \\
126 \\
63 \\
622 \\
321\end{array}$ & $\begin{array}{l}2.06 \\
6.86 \\
4.44 \\
9.14 \\
1.66\end{array}$ & $\begin{array}{l}4.0 \\
5.3 \\
6.9 \\
1.4 \\
.5\end{array}$ & $\begin{array}{l}7.41 \\
6.68 \\
14.4 \\
13.0 \\
38.6\end{array}$ & $\begin{array}{l}7.50 \\
7.01 \\
16.8 \\
14.3 \\
39.5\end{array}$ & $\begin{array}{r}16 \\
362 \\
24^{+} \\
5751 \\
101\end{array}$ & $\begin{array}{l}.18 \\
.13 \\
.58 \\
.09 \\
.04\end{array}$ \\
\hline $\begin{array}{l}\text { cVnII } \\
\text { N3184 } \\
\text { Coma I } \\
\text { N6300 } \\
\text { Cet I }\end{array}$ & $\begin{array}{l}x \\
x \\
x\end{array}$ & $\begin{array}{l}10 \\
12 \\
13 \\
14 \\
15\end{array}$ & $\begin{array}{r}6 \\
4 \\
14 \\
3 \\
6\end{array}$ & $\begin{array}{l}14.1 \\
13.0 \\
20.2 \\
23.5 \\
25.0\end{array}$ & $\begin{array}{l}152 \\
120 \\
352 \\
253 \\
288\end{array}$ & $\begin{array}{l}2.15 \\
1.08 \\
1.46 \\
1.07 \\
1.52\end{array}$ & $\begin{array}{l}1.4 \\
.9 \\
.4 \\
.4 \\
.5\end{array}$ & $\begin{array}{r}1.00 \\
1.00 \\
.77 \\
1.00 \\
.90\end{array}$ & $\begin{array}{l}124 \\
101 \\
358 \\
226 \\
271\end{array}$ & $\begin{array}{l}1.61 \\
5.49 \\
3.80 \\
1.42 \\
3.03\end{array}$ & $\begin{array}{r}1.3 \\
5.3 \\
1.0 \\
.6 \\
1.1\end{array}$ & $\begin{array}{c}20.9 \\
7.04 \\
40.0 \\
19.9 \\
35.5\end{array}$ & $\begin{array}{c}24.6 \\
8.09 \\
42.0 \\
43.7 \\
57.4\end{array}$ & $\begin{array}{r}23 \\
160 \\
269 \\
39 \\
90\end{array}$ & $\begin{array}{l}.23 \\
.13 \\
.13 \\
.78 \\
.06\end{array}$ \\
\hline $\begin{array}{l}\text { N1566 } \\
\text { U MaI }(z) \\
\text { Vir S } \\
\text { Vir E } \\
\text { Vir Y }\end{array}$ & $\mathrm{x}$ & $\begin{array}{l}16 \\
17 \\
18 \\
19 \\
20\end{array}$ & $\begin{array}{r}12 \\
4 \\
5 \\
5 \\
4\end{array}$ & $\begin{array}{l}20.1 \\
20.6 \\
26.2 \\
18.9 \\
25.0\end{array}$ & $\begin{array}{r}408 \\
72 \\
1683 \\
345 \\
226\end{array}$ & $\begin{array}{l}.72 \\
1.01 \\
1.25 \\
1.31 \\
1.67\end{array}$ & $\begin{array}{r}.2 \\
1.4 \\
.1 \\
.4 \\
.7\end{array}$ & $\begin{array}{r}.46 \\
.74 \\
1.00 \\
.00 \\
.50\end{array}$ & $\begin{array}{r}337 \\
66 \\
1754 \\
315 \\
173\end{array}$ & $\begin{array}{l}1.52 \\
2.90 \\
4.93 \\
5.70 \\
4.90\end{array}$ & $\begin{array}{r}.4 \\
4.3 \\
.3 \\
1.8 \\
2.8\end{array}$ & $\begin{array}{c}32.3 \\
7.47 \\
54.0 \\
32.6 \\
25.0\end{array}$ & $\begin{array}{c}35.1 \\
8.82 \\
212.1 \\
66.1 \\
42.7\end{array}$ & $\begin{array}{r}114 \\
33^{x} \\
1660 \\
198 \\
80\end{array}$ & $\begin{array}{l}.08 \\
.79 \\
.02 \\
.11 \\
.48\end{array}$ \\
\hline $\begin{array}{l}\text { N1433 } \\
\text { N1672 } \\
\text { Vir S' } \\
\text { Vir X } \\
\text { Grus }\end{array}$ & $x$ & $\begin{array}{l}21 \\
22 \\
25 \\
26 \\
27\end{array}$ & $\begin{array}{r}5 \\
4 \\
3 \\
5 \\
14\end{array}$ & $\begin{array}{l}16.8 \\
20.5 \\
32.9 \\
23.9 \\
30.1\end{array}$ & $\begin{array}{r}219 \\
164 \\
1336 \\
523 \\
426\end{array}$ & $\begin{array}{r}.78 \\
1.20 \\
.60 \\
1.11 \\
2.11\end{array}$ & $\begin{array}{l}.4 \\
.7 \\
.04 \\
.2 \\
.5\end{array}$ & $\begin{array}{r}.76 \\
1.00 \\
1.00 \\
.74 \\
.74\end{array}$ & $\begin{array}{l}250 \\
103 \\
807 \\
550 \\
470\end{array}$ & $\begin{array}{l}3.52 \\
4.82 \\
4.97 \\
3.56 \\
2.70\end{array}$ & $\begin{array}{r}1.4 \\
4.6 \\
.6 \\
.6 \\
.6\end{array}$ & $\begin{array}{l}9.24 \\
9.73 \\
19.1 \\
30.2 \\
56.0\end{array}$ & $\begin{array}{l}10.3 \\
10.7 \\
27.0 \\
52.9 \\
76.9\end{array}$ & $\begin{array}{r}495 \\
111 \\
2785 \\
473 \\
181\end{array}$ & $\begin{array}{r}.27 \\
1.02 \\
.16 \\
.05 \\
.05\end{array}$ \\
\hline $\begin{array}{l}\operatorname{UMaI}(\mathrm{x}) \\
\operatorname{Vir} \text { III } \\
\text { N5866 } \\
\text { Eri I } \\
\text { U MaI(s) }\end{array}$ & $\begin{array}{l}x \\
x\end{array}$ & $\begin{array}{l}29 \\
29 \\
30 \\
31 \\
32\end{array}$ & $\begin{array}{r}4 \\
5 \\
3 \\
21 \\
5\end{array}$ & $\begin{array}{l}31.8 \\
32.8 \\
17.5 \\
30.4 \\
17.2\end{array}$ & $\begin{array}{r}17.32 \\
281 \\
67 \\
331 \\
255\end{array}$ & $\begin{array}{r}1.51 \\
2.47 \\
.30 \\
2.41 \\
.97\end{array}$ & $\begin{array}{l}.1 \\
.9 \\
.4 \\
.7 \\
.4\end{array}$ & $\begin{array}{r}1.00 \\
.87 \\
.68 \\
.68 \\
1.00\end{array}$ & $\begin{array}{r}1130 \\
250 \\
58 \\
281 \\
270\end{array}$ & $\begin{array}{c}7.65 \\
11.2 \\
2.20 \\
6.98 \\
4.21\end{array}$ & $\begin{array}{l}.6 \\
4.4 \\
3.7 \\
2.4 \\
1.5\end{array}$ & $\begin{array}{l}18.1 \\
25.1 \\
7.50 \\
89.2 \\
12.7\end{array}$ & $\begin{array}{c}24.8 \\
41.2 \\
9.13 \\
101.3 \\
15.9\end{array}$ & $\begin{array}{r}9153 \\
394 \\
19 \\
127 \\
450\end{array}$ & $\begin{array}{l}.02 \\
.26 \\
.24 \\
.16 \\
.15\end{array}$ \\
\hline $\begin{array}{l}\text { CET II } \\
\text { U MaI (N) } \\
\text { Vir V } \\
\text { N2207 } \\
\text { N5676 }\end{array}$ & & $\begin{array}{l}33 \\
34 \\
35 \\
36 \\
37\end{array}$ & $\begin{array}{l}5 \\
5 \\
4 \\
5 \\
4\end{array}$ & $\begin{array}{l}37.1 \\
22.8 \\
17.7 \\
38.4 \\
46.3\end{array}$ & $\begin{array}{r}313 \\
163 \\
86 \\
943 \\
238\end{array}$ & $\begin{array}{l}3.27 \\
1.20 \\
1.03 \\
3.21 \\
1.28\end{array}$ & $\begin{array}{r}1.0 \\
.7 \\
1.2 \\
.3 \\
.5\end{array}$ & $\begin{array}{r}.33 \\
1.00 \\
.51 \\
.78 \\
.86\end{array}$ & $\begin{array}{r}276 \\
130 \\
87 \\
879 \\
180\end{array}$ & $\begin{array}{c}4.85 \\
4.36 \\
2.54 \\
13.7 \\
4.08\end{array}$ & $\begin{array}{l}1.7 \\
3.3 \\
2.9 \\
1.5 \\
2.2\end{array}$ & $\begin{array}{c}26.9 \\
20.7 \\
5.91 \\
46.9 \\
22.3\end{array}$ & $\begin{array}{c}44.1 \\
31.4 \\
6.50 \\
126.0 \\
34.5\end{array}$ & $\begin{array}{r}195 \\
54 \\
69 \\
1951 \\
89\end{array}$ & $\begin{array}{l}.26 \\
.24 \\
.34 \\
.08 \\
.21\end{array}$ \\
\hline $\begin{array}{l}\text { N134 } \\
\text { N488 } \\
\text { N2768 } \\
\text { N2964 } \\
\text { N3396 }\end{array}$ & & $\begin{array}{l}39 \\
40 \\
41 \\
42 \\
43\end{array}$ & $\begin{array}{l}4 \\
4 \\
5 \\
5 \\
3\end{array}$ & $\begin{array}{l}31.9 \\
48.8 \\
30.5 \\
29.1 \\
32.0\end{array}$ & $\begin{array}{r}191 \\
245 \\
282 \\
203 \\
59\end{array}$ & $\begin{array}{r}1.76 \\
1.08 \\
1.41 \\
1.80 \\
.16\end{array}$ & $\begin{array}{l}.9 \\
.4 \\
.5 \\
.9 \\
.3\end{array}$ & $\begin{array}{r}.94 \\
.80 \\
.56 \\
.62 \\
1.00\end{array}$ & $\begin{array}{r}172 \\
204 \\
222 \\
234 \\
60\end{array}$ & $\begin{array}{r}12.2 \\
2.20 \\
3.64 \\
7.40 \\
.28\end{array}$ & $\begin{array}{r}6.9 \\
1.1 \\
1.6 \\
3.1 \\
.5\end{array}$ & $\begin{array}{c}18.1 \\
34.2 \\
17.0 \\
12.2 \\
9.35\end{array}$ & $\begin{array}{l}24.2 \\
69.8 \\
21.7 \\
14.7 \\
12.7\end{array}$ & $\begin{array}{r}344 \\
30 \\
192 \\
643 \\
2\end{array}$ & $\begin{array}{l}.67 \\
.24 \\
.69 \\
.56 \\
.36\end{array}$ \\
\hline $\begin{array}{l}\text { N3923 } \\
\text { Pav-Ind } \\
\text { Vir W } \\
\text { N3190 } \\
\text { N3504 }\end{array}$ & & $\begin{array}{l}44 \\
45 \\
46 \\
47 \\
48\end{array}$ & $\begin{array}{l}4 \\
5 \\
4 \\
5 \\
3\end{array}$ & $\begin{array}{l}32.1 \\
38.6 \\
42.4 \\
24.5 \\
27.9\end{array}$ & $\begin{array}{r}343 \\
797 \\
426 \\
59 \\
95\end{array}$ & $\begin{array}{r}1.32 \\
5.87 \\
.30 \\
.71 \\
.68\end{array}$ & $\begin{array}{r}.4 \\
.7 \\
.1 \\
1.2 \\
.7\end{array}$ & $\begin{array}{l}.00 \\
.70 \\
.41 \\
.72 \\
.67\end{array}$ & $\begin{array}{r}283 \\
890 \\
403 \\
42 \\
98\end{array}$ & $\begin{array}{r}.69 \\
22.1 \\
1.08 \\
.43 \\
.88\end{array}$ & $\begin{array}{r}.2 \\
2.4 \\
.3 \\
1.0 \\
.9\end{array}$ & $\begin{array}{c}16.8 \\
30.8 \\
18.5 \\
9.50 \\
6.57\end{array}$ & $\begin{array}{c}23.9 \\
59.6 \\
29.7 \\
11.1 \\
7.79\end{array}$ & $\begin{array}{r}54 \\
6840 \\
137 \\
2 \\
25\end{array}$ & $\begin{array}{r}.32 \\
.15 \\
.24 \\
1.91 \\
.89\end{array}$ \\
\hline $\begin{array}{l}\text { N3607 } \\
\text { N5846 } \\
\text { N6643 } \\
\text { N6861 } \\
\text { For I }\end{array}$ & $\begin{array}{l}x \\
x \\
x\end{array}$ & $\begin{array}{l}49 \\
50 \\
51 \\
52 \\
53\end{array}$ & $\begin{array}{r}5 \\
5 \\
5 \\
11 \\
7\end{array}$ & $\begin{array}{l}21.1 \\
36.6 \\
33.0 \\
55.4 \\
31.6\end{array}$ & $\begin{array}{l}246 \\
725 \\
342 \\
396 \\
362\end{array}$ & $\begin{array}{l}.56 \\
.58 \\
2.36 \\
2.59 \\
1.29\end{array}$ & $\begin{array}{l}.2 \\
.1 \\
.7 \\
.6 \\
.4\end{array}$ & $\begin{array}{l}.30 \\
.35 \\
.70 \\
.14 \\
.08\end{array}$ & $\begin{array}{l}299 \\
740 \\
321 \\
352 \\
304\end{array}$ & $\begin{aligned} & .76 \\
& 1.33 \\
& 11.8 \\
& 3.28 \\
& 1.89\end{aligned}$ & $\begin{array}{r}.2 \\
.2 \\
3.6 \\
.9 \\
.6\end{array}$ & $\begin{array}{l}7.30 \\
24.6 \\
19.5 \\
58.7 \\
57.3\end{array}$ & $\begin{array}{r}8.05 \\
41.7 \\
28.2 \\
98.9 \\
102.5\end{array}$ & $\begin{array}{r}195 \\
406 \\
1005 \\
96 \\
40\end{array}$ & $\begin{array}{l}.34 \\
.07 \\
.20 \\
.07 \\
.18\end{array}$ \\
\hline $\begin{array}{l}\text { N3245 } \\
\text { Ant1ia } \\
\text { Hydra IICL } \\
\text { N3557 } \\
\text { Centaurus }\end{array}$ & $\begin{array}{l}x \\
x \\
x \\
x\end{array}$ & 54 & $\begin{array}{l}3 \\
6 \\
4 \\
3 \\
6\end{array}$ & $\begin{array}{l}26.0 \\
52.5 \\
73.9 \\
50.5 \\
62.5\end{array}$ & $\begin{array}{r}144 \\
1146 \\
1506 \\
539 \\
1098\end{array}$ & $\begin{array}{r}.40 \\
1.61 \\
.13 \\
.14 \\
.86\end{array}$ & $\begin{array}{l}.3 \\
.1 \\
.009 \\
.03 \\
.08\end{array}$ & $\begin{array}{l}.62 \\
.41 \\
.37 \\
.00 \\
.00\end{array}$ & $\begin{array}{l}103 \\
604 \\
850 \\
251 \\
540\end{array}$ & $\begin{array}{r}2.79 \\
3.30 \\
.43 \\
.84 \\
2.73\end{array}$ & $\begin{array}{l}2.7 \\
.5 \\
.05 \\
.3 \\
.5\end{array}$ & $\begin{array}{l}6.01 \\
36.1 \\
33.5 \\
19.3 \\
35.8\end{array}$ & $\begin{array}{l}7.08 \\
61.0 \\
76.7 \\
29.9 \\
55.1\end{array}$ & $\begin{array}{r}97 \\
459 \\
95 \\
41 \\
336\end{array}$ & $\begin{array}{l}.80 \\
.07 \\
.05 \\
.26 \\
.07\end{array}$ \\
\hline $\begin{array}{l}\text { I4296 } \\
\text { I4329 } \\
\text { N5898 } \\
\text { N6769 } \\
\text { Pavo }\end{array}$ & $\begin{array}{l}x \\
x \\
x \\
x \\
x\end{array}$ & & $\begin{array}{l}3 \\
5 \\
3 \\
5 \\
4\end{array}$ & $\begin{array}{l}73.0 \\
86.4 \\
45.2 \\
79.1 \\
80.2\end{array}$ & $\begin{array}{l}223 \\
932 \\
166 \\
390 \\
891\end{array}$ & $\begin{array}{c}1.29 \\
1.88 \\
.049 \\
1.27 \\
.27\end{array}$ & $\begin{array}{l}.6 \\
.2 \\
.03 \\
.3 \\
.03\end{array}$ & $\begin{array}{l}.13 \\
.00 \\
.00 \\
.50 \\
.58\end{array}$ & $\begin{array}{l}183 \\
993 \\
199 \\
236 \\
588\end{array}$ & $\begin{array}{r}2.47 \\
1.84 \\
.38 \\
.54 \\
.39\end{array}$ & $\begin{array}{l}1.3 \\
.2 \\
.2 \\
.2 \\
.07\end{array}$ & $\begin{array}{c}33.2 \\
42.1 \\
6.21 \\
44.6 \\
34.3\end{array}$ & $\begin{array}{c}93.6 \\
85.2 \\
7.83 \\
103.1 \\
47.0\end{array}$ & $\begin{array}{r}20 \\
495 \\
45 \\
7 \\
67\end{array}$ & $\begin{array}{l}.44 \\
.05 \\
.47 \\
.26 \\
.19\end{array}$ \\
\hline $\begin{array}{l}\text { N7049 } \\
\text { N7144 } \\
\text { N7213 }\end{array}$ & $\begin{array}{l}\mathrm{x} \\
\mathrm{x} \\
\mathrm{x}\end{array}$ & & $\begin{array}{l}3 \\
3 \\
3\end{array}$ & $\begin{array}{l}45.1 \\
38.4 \\
38.0\end{array}$ & $\begin{array}{l}637 \\
249 \\
245\end{array}$ & $\begin{array}{l}.56 \\
.54 \\
.74\end{array}$ & $\begin{array}{l}.09 \\
.2 \\
.3\end{array}$ & $\begin{array}{l}.00 \\
.00 \\
.80\end{array}$ & $\begin{array}{l}530 \\
197 \\
238\end{array}$ & $\begin{array}{l}2.52 \\
2.04 \\
3.95\end{array}$ & $\begin{array}{l}.5 \\
1.0 \\
1.6\end{array}$ & $\begin{array}{r}15.0 \\
8.9 \\
12.7\end{array}$ & $\begin{array}{l}27.5 \\
11.4 \\
17.4\end{array}$ & $\begin{array}{l}598 \\
161 \\
299\end{array}$ & $\begin{array}{l}.11 \\
.49 \\
.35\end{array}$ \\
\hline
\end{tabular}


TABLE 2

Virial Properties of TG Groups

\begin{tabular}{|c|c|c|c|c|c|c|c|c|c|c|c|c|c|c|}
\hline $\begin{array}{l}\text { Group } \\
\mathrm{deV}\end{array}$ & $\begin{array}{l}\text { Group } \\
\text { TG }\end{array}$ & $\mathrm{N}$ & $\begin{array}{l}d_{c m} \\
M p c\end{array}$ & $\begin{array}{l}\langle\mathrm{v}\rangle \\
\mathrm{km} \mathrm{s}\end{array}$ & $\begin{array}{l}\langle r> \\
M p c\end{array}$ & ${ }_{10}^{t_{c}}{ }^{10}$ yrs & $\mathrm{f}_{\mathrm{s}}$ & $\begin{array}{l}\mathrm{V} \\
\mathrm{km} \mathrm{s}\end{array}$ & $\begin{array}{l}\mathrm{R} \\
\mathrm{Mpc}\end{array}$ & $\begin{array}{l}{ }^{t} \mathrm{VT} \\
10^{10} \mathrm{yrs}\end{array}$ & ${ }_{10}^{\mathrm{L}}{ }^{10_{\mathrm{LO}}}$ & $\begin{array}{l}\mathrm{L}_{\mathrm{T}} \\
10^{10_{\mathrm{L}}}\end{array}$ & $\frac{\mathrm{MVT}_{\mathrm{T}}^{\mathrm{M}}}{\text { solar }}$ & $\frac{\sigma\left(v^{2}\right)}{v^{2}}$ \\
\hline $\begin{array}{l}2 \\
47 \\
(9+11) \\
43\end{array}$ & $\begin{array}{l}6 \\
16 \\
21 \mathrm{~A} \\
27 \mathrm{~A} \\
28\end{array}$ & $\begin{array}{l}3 \\
4 \\
5 \\
6 \\
4\end{array}$ & $\begin{array}{c}36.3 \\
3.26 \\
24.3 \\
14.1 \\
32.3\end{array}$ & $\begin{array}{r}56 \\
157 \\
90 \\
124 \\
102\end{array}$ & $\begin{array}{l}.074 \\
.051 \\
.32 \\
.26 \\
.32\end{array}$ & $\begin{array}{l}.1 \\
.03 \\
.3 \\
.2 \\
.3\end{array}$ & $\begin{array}{r}1.00 \\
1.00 \\
.76 \\
.50 \\
1.00\end{array}$ & $\begin{array}{r}29 \\
193 \\
58 \\
101 \\
80\end{array}$ & $\begin{array}{l}.46 \\
.29 \\
.51 \\
.60 \\
.33\end{array}$ & $\begin{array}{r}1.6 \\
.1 \\
.9 \\
.6 \\
.4\end{array}$ & $\begin{array}{c}9.25 \\
2.53 \\
6.63 \\
11.7 \\
10.9\end{array}$ & $\begin{array}{c}11.7 \\
2.53 \\
7.06 \\
13.2 \\
14.1\end{array}$ & $\begin{array}{r}1 \\
98 \\
6 \\
11 \\
3\end{array}$ & $\begin{array}{r}5.56 \\
.06 \\
1.98 \\
.42 \\
.99\end{array}$ \\
\hline $\begin{array}{l}(9+11) \\
49\end{array}$ & $\begin{array}{l}38 \\
39 \mathrm{~A} \\
40 \\
47 \mathrm{~A} \\
50 \mathrm{~A}\end{array}$ & $\begin{array}{r}4 \\
9 \\
3 \\
21 \\
24\end{array}$ & $\begin{array}{l}13.6 \\
21.9 \\
24.8 \\
27.3 \\
15.1\end{array}$ & $\begin{array}{l}148 \\
357 \\
122 \\
704 \\
445\end{array}$ & $\begin{array}{r}.16 \\
.56 \\
.24 \\
1.87 \\
.98\end{array}$ & $\begin{array}{l}.1 \\
.2 \\
.2 \\
.3 \\
.2\end{array}$ & $\begin{array}{l}.95 \\
.48 \\
.27 \\
.67 \\
.95\end{array}$ & $\begin{array}{r}110 \\
349 \\
54 \\
721 \\
400\end{array}$ & $\begin{array}{r}.60 \\
.85 \\
1.39 \\
3.63 \\
2.35\end{array}$ & $\begin{array}{r}.5 \\
.2 \\
2.5 \\
.5 \\
.6\end{array}$ & $\begin{array}{r}13.7 \\
11.7 \\
4.6 \\
53.0 \\
39.0\end{array}$ & $\begin{array}{c}19.2 \\
12.7 \\
4.93 \\
59.2 \\
40.5\end{array}$ & $\begin{array}{r}9 \\
189 \\
19 \\
741 \\
216\end{array}$ & $\begin{array}{r}.14 \\
.19 \\
7.39 \\
.04 \\
.06\end{array}$ \\
\hline (13) & $\begin{array}{l}51 \\
53 \mathrm{~A} \\
46 \mathrm{~B} \\
56 \mathrm{~A} \\
56 \mathrm{~B}\end{array}$ & $\begin{array}{r}5 \\
15 \\
3 \\
8 \\
5\end{array}$ & $\begin{array}{l}18.0 \\
15.1 \\
63.8 \\
55.1 \\
30.2\end{array}$ & $\begin{array}{r}191 \\
396 \\
31 \\
256 \\
93\end{array}$ & $\begin{array}{r}.35 \\
.55 \\
1.02 \\
1.75 \\
.76\end{array}$ & $\begin{array}{r}.2 \\
.1 \\
3.2 \\
.7 \\
.8\end{array}$ & $\begin{array}{l}.39 \\
.73 \\
.00 \\
.83 \\
.25\end{array}$ & $\begin{array}{r}145 \\
340 \\
<\quad 30 \\
225 \\
50\end{array}$ & $\begin{array}{l}1.37 \\
1.43 \\
6.09 \\
4.18 \\
3.60\end{array}$ & $\begin{array}{r}.9 \\
.4 \\
20.0 \\
1.8 \\
7.0\end{array}$ & $\begin{array}{l}4.89 \\
11.7 \\
12.7 \\
43.1 \\
11.0\end{array}$ & $\begin{array}{l}5.08 \\
12.0 \\
20.0 \\
75.1 \\
11.9\end{array}$ & $\begin{array}{r}132 \\
322 \\
<\quad 6 \\
55 \\
18\end{array}$ & $\begin{array}{r}.86 \\
.14 \\
>4.78 \\
.26 \\
1.43\end{array}$ \\
\hline (13) & $\begin{array}{l}58 \\
64 \\
67 \\
77 \\
78\end{array}$ & $\begin{array}{r}4 \\
3 \\
3 \\
10 \\
5\end{array}$ & $\begin{array}{l}38.6 \\
23.9 \\
19.9 \\
50.5 \\
39.0\end{array}$ & $\begin{array}{r}120 \\
91 \\
204 \\
202 \\
330\end{array}$ & $\begin{array}{r}.56 \\
.42 \\
.17 \\
1.20 \\
.74\end{array}$ & $\begin{array}{l}.5 \\
.4 \\
.08 \\
.6 \\
.2\end{array}$ & $\begin{array}{r}.26 \\
.95 \\
1.00 \\
.79 \\
.11\end{array}$ & $\begin{array}{r}56 \\
62 \\
132 \\
196 \\
317\end{array}$ & $\begin{array}{l}1.03 \\
4.47 \\
1.34 \\
1.20 \\
3.10\end{array}$ & $\begin{array}{l}1.8 \\
7.1 \\
1.0 \\
.6 \\
1.0\end{array}$ & $\begin{array}{l}12.6 \\
10.6 \\
10.5 \\
57.5 \\
20.2\end{array}$ & $\begin{array}{l}17.4 \\
11.5 \\
16.1 \\
83.5 \\
26.3\end{array}$ & $\begin{array}{r}4 \\
34 \\
33 \\
13 \\
275\end{array}$ & $\begin{array}{r}4.22 \\
.17 \\
.32 \\
.24 \\
.26\end{array}$ \\
\hline 37 & $\begin{array}{l}82 \mathrm{~A} \\
86 \\
87 \\
91 \\
98\end{array}$ & $\begin{array}{l}3 \\
5 \\
3 \\
6 \\
3\end{array}$ & $\begin{array}{l}39.2 \\
67.1 \\
30.2 \\
47.0 \\
41.6\end{array}$ & $\begin{array}{l}579 \\
572 \\
139 \\
237 \\
355\end{array}$ & $\begin{array}{r}.17 \\
1.22 \\
.26 \\
1.09 \\
.12\end{array}$ & $\begin{array}{l}.03 \\
.2 \\
.2 \\
.4 \\
.03\end{array}$ & $\begin{array}{l}.28 \\
.67 \\
.65 \\
.89 \\
1.00\end{array}$ & $\begin{array}{r}525 \\
690 \\
86 \\
207 \\
308\end{array}$ & $\begin{array}{r}.76 \\
3.84 \\
.91 \\
2.00 \\
.15\end{array}$ & $\begin{array}{l}.1 \\
.5 \\
1.0 \\
.9 \\
.05\end{array}$ & $\begin{array}{c}8.25 \\
47.3 \\
9.16 \\
30.3 \\
8.98\end{array}$ & $\begin{array}{r}10.6 \\
130.8 \\
11.3 \\
47.1 \\
11.8\end{array}$ & $\begin{array}{r}457 \\
325 \\
14 \\
42 \\
29\end{array}$ & $\begin{array}{r}.10 \\
.11 \\
1.59 \\
.22 \\
.40\end{array}$ \\
\hline $\begin{array}{l}50 \\
(9+11)\end{array}$ & $\begin{array}{l}95 \\
27 \mathrm{~B} \\
47 \mathrm{~B} \\
53 \mathrm{~B}\end{array}$ & $\begin{array}{r}12 \\
3 \\
8 \\
6\end{array}$ & $\begin{array}{l}35.1 \\
23.2 \\
62.9 \\
65.9\end{array}$ & $\begin{array}{r}489 \\
42 \\
303 \\
847\end{array}$ & $\begin{array}{r}1.01 \\
.55 \\
3.25 \\
4.01\end{array}$ & $\begin{array}{r}.2 \\
1.3 \\
1.0 \\
.5\end{array}$ & $\begin{array}{r}.40 \\
1.00 \\
.92 \\
.70\end{array}$ & $\begin{array}{r}621 \\
24 \\
261 \\
834\end{array}$ & $\begin{array}{r}1.43 \\
3.73 \\
.36 \\
1.48\end{array}$ & $\begin{array}{r}.2 \\
15.5 \\
.1 \\
.2\end{array}$ & $\begin{array}{c}35.8 \\
6.70 \\
78.4 \\
40.2\end{array}$ & $\begin{array}{c}39.1 \\
7.58 \\
178.8 \\
71.8\end{array}$ & $\begin{array}{r}329 \\
6 \\
3 \\
332\end{array}$ & $\begin{array}{r}.07 \\
1.85 \\
.37 \\
.21\end{array}$ \\
\hline
\end{tabular}

\section{Notes to TABLES 1 AND 2}

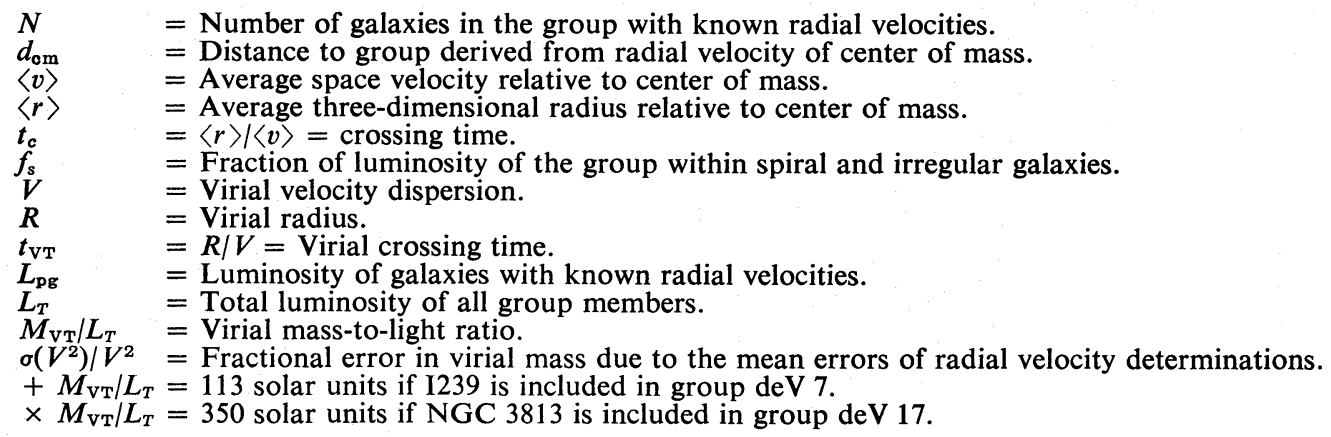

members are excluded; the notes contain values if the doubtful galaxies are included.)

In another analysis, Turner and Gott (1976a) constructed a catalog of groups from a study of the surface distribution of galaxies brighter than 14th magnitude listed in the catalogs of Zwicky et al. (19601968) and Nilson (1973) and located only at northern declinations and Galactic latitudes. Surface-density enhancements corresponding typically to a volume- density contrast of a factor of 10 greater than the average density were identified as group candidates by well-defined procedures carried out by computer. Final decisions on group membership were made by human judgment from known systemic velocities. In the present study, we have relied on the judgment of Turner and Gott, modified only by new radial-velocity determinations by Kirshner (1977) and the present authors. The groups identified in this manner, but not 
including the rich Virgo, Coma, and A1367 clusters, will be called TG groups. The 29 TG groups with three or more known galactic redshifts are listed in Table 2.

Since the classical and Turner-Gott selection criteria are similar in basic respects, it is natural that several groups are common to both the STV and TG samples. Some TG groups are too distant to be found among the STV groups. Many STV groups lie outside the TG survey area. However, a small number of STV groups are inexplicably absent from the TG groups, and vice versa.

Virial properties of the STV and TG groups are tabulated in Tables 1 and 2. They were derived from the galaxies with known radial velocities in the groups. These tend to be the brightest group members. The properties of a given group can sometimes be different in the two different surveys because of differing membership criteria.

The photographic luminosities in solar units of the observed members of a group on the Holmberg (1958) system, $L_{\mathrm{pg}}$, were derived from magnitudes given by Holmberg (1958), de Vaucouleurs, de Vaucouleurs, and Corwin (1976), de Vaucouleurs and de Vaucouleurs (1964), and Zwicky et al. (1960-1968), transformed to the Holmberg system with relations derived by Dickel and Rood (1978). The magnitudes were corrected for internal and Galactic extinction following Dickel and Rood (1978). The internal extinction correction is about half of that derived by Holmberg (1958), and the Galactic extinction at the poles is $0.22 \mathrm{mag}$ (Holmberg 1958, 1974). The adopted absolute photographic magnitude of the Sun is 5.16 mag (Allen 1955). The distance to each group was derived from the radial velocity of its center of mass and an adopted Hubble constant of $H=50 \mathrm{~km} \mathrm{~s}^{-1} \mathrm{Mpc}^{-1}$. Turner and Gott (1976b) show that the luminosity function of a group is well represented by a Schechter (1976) function. They show that, for this case, the total luminosity of a group, $L_{T}$, is related to the summed luminosity, $L_{0}$, of the galaxies as bright or brighter than some chosen limiting luminosity $L_{c}$ by

$$
\ln L_{0}=\ln L_{T}-\frac{L_{c}}{L^{*}}
$$

where $\ln$ is the natural logarithm and $L^{*}$ is a characteristic luminosity which is believed to be the same for all groups (Turner and Gott 1976b), as appears to be the case for rich clusters (Abell 1975). Consequently, $L^{*}$ can be derived from the value of the slope of the regression line relating $\ln L_{0}$ to $L_{c}$ for all group members. We find $L^{*}=(7.5 \pm 0.5) \times 10^{10}$ solar units from the STV sample, and $L^{*}=(5.1 \pm 0.5) \times 10^{10}$ solar units from the TG sample. To evaluate $L_{T}$ for both the STV and TG groups, we adopted $L^{*}=$ $6.3 \times 10^{10}$ solar units. For each group, $L_{T}$ was derived from equation (1) with $L_{c}$ equal to that of $(a)$ the faintest observed group member, and $(b)$ the next-tofaintest group member. To reduce errors, the average of these two determinations of $L_{T}$ was adopted and is listed in Tables 1 and 2.
The virial mass of a group, $M_{\mathrm{VT}}$, is given by

$$
M_{\mathrm{VT}}=\frac{V^{2} R}{G}
$$

where $G$ is the gravitational constant, $V$ (called the virial velocity dispersion) is the mass-weighted velocity dispersion of the galaxies, and $R$ (the virial radius) is approximately twice the harmonic average separation of group members weighted by their mass products (see Rood, Rothman, and Turnrose 1970 for the precise definition). These parameters, corrected for the mean errors of the radial velocity measurements by the procedure given by Materne (1974), were evaluated from the relations summarized by Rood and Dickel (1976). The observational data needed are locations, radial velocities, their mean errors, and the masses of individual group members.

The radial velocities and mean errors were taken from the $21 \mathrm{~cm}$ survey with the 300 foot $(91 \mathrm{~m})$ telescope of the National Radio Astronomy Observatory ${ }^{1}$ by Dickel and Rood (1978), the Second Reference Catalog of de Vaucouleurs, de Vaucouleurs, and Corwin (1976) (which includes data from the $21 \mathrm{~cm}$ surveys of Shostak 1975 and Fisher and Tully 1975), Balick, Faber, and Gallagher (1976), Martin (1976), de Vaucouleurs, Shobbrook, and Strobel (1976), Huchtmeier, Tammann, and Wendker (1976), and Kirshner (1977). Additional $21 \mathrm{~cm}$ velocities of STV and TG galaxies without velocities listed in these sources were kindly made available to us by G. Knapp and by R. B. Tully from their extensive surveys.

The integrated masses of spiral and irregular galaxies derived from a small number of detailed rotation curves by Lewis and Robinson (1973) and Huchtmeier (1975) were adopted in our analysis when available. Otherwise, we used Brandt masses derived by the procedures of Dickel and Rood (1978) from the accurate global half-widths of $21 \mathrm{~cm}$ hydrogen line profiles observed by Fisher and Tully (1975), Shostak (1975), Huchtmeier, Tammann, and Wendker (1976), and Dickel and Rood (1978). For elliptical and S0 galaxies, and when half-widths were not available for spirals, we used the galactic luminosities multiplied by a mass-to-light ratio of 10.2 solar units (the weighted average value derived by Dickel and Rood 1978).

Our justification for adopting the Brandt extrapolation for the integrated masses of the galaxies when available is based upon the work of Huchtmeier (1975), who has shown that the observed portions of the rotation curves in his sample-which sometimes extend beyond 3 Holmberg radii-can be approximated by Brandt curves. The Brandt mass is $V_{m}^{2} R_{m} f(n)$, where $V_{m}$ and $R_{m}$ are the rotational velocity and the radial distance of the maximum in the rotation curve, and $f(n)$ is a function depending on the shape of the rotation curve. If the Brandt mass

\footnotetext{
${ }^{1}$ The National Radio Astronomy Observatory is operated by Associated Universities, Inc., under contract with the National Science Foundation.
} 
differs from the actual integrated mass of a galaxy by a constant factor which is independent of galactic luminosity or morphological type, then this error does not cause errors in the calculated virial parameters.

We believe that Brandt masses are better estimates of integrated masses of galaxies than the two other competing alternatives: (a) the mass within a Holmberg radius or $(b)$ the galactic luminosity multiplied by a constant. The mass within a Holmberg radius is likely to be a different fraction of the integrated mass for galaxies with rotation curve maxima occurring near the Holmberg radius than for galaxies with the maxima at a small fraction of the Holmberg radius. Two morphologically similar galaxies with the same luminosity and $R_{m}$ but with different $V_{m}$ are likely to have different integrated masses. Similarly, two morphologically similar galaxies with the same luminosity and $V_{m}$ but with different $R_{m}$ are likely to have different integrated masses.

The virial mass-to-light ratio, $M_{\mathrm{VT}} / L_{T}$, and other parameters are tabulated for the STV and TG groups in Tables 1 and 2 . Included in the listings are the fraction of the light contained in spiral and irregular galaxies, $f_{s}$, the fractional mean error in a virial mass determination due to random errors in the radial velocity measurements, $\sigma\left(V^{2}\right) / V^{2}$, and the virial crossing time, $t_{\mathrm{VT}}=R / V$. This latter quantity has been evaluated for comparison with previous work only. Jackson (1975) has shown that $t_{\mathrm{VT}}$ is not appropriate for testing whether or not a group is freely expanding in the Hubble flow. A parameter which is appropriate for that purpose, which we will call simply the "crossing time," is $t_{c}=\langle r\rangle \mid\langle v\rangle$, where $\langle r\rangle$ is the average radial distance of group members from the center of mass of the group, and $\langle v\rangle$ is the average of the absolute value of the galaxies' velocities relative to the center of mass. The average projection factor to convert from observed radial distance to actual three-dimensional radial distance is $4 / \pi$, and the factor from line-of-sight relative velocity to space relative velocity is 2 . The crossing time $t_{c}$ of a freely expanding group is approximately equal to the time elapsed since the expansion began. Values of $t_{c},\langle r\rangle$, and $\langle v\rangle$ are listed in Tables 1 and 2 .

\section{RESULTS}

\section{a) Mass-to-Light Ratios}

The frequency distributions of $\log M_{\mathrm{VT}} / L_{T}$ for the STV and TG groups are presented in Figure 1 and the median mass-to-light ratios of various selections of groups are presented in Table 3. The STV groups, on the average, tend to have larger mass-to-light ratios than the TG groups, but there is a considerable spread in values. The mass-to-light ratios of the wellknown groups listed by Sandage and Tammann (1975) are about the same as the mass-to-light ratios of additional de Vaucouleurs (1975) groups and Sandage (1975) groups; the median $M_{\mathrm{VT}} / L_{T}$ of all STV groups combined is 127 solar units. When groups in the dense Virgo region are omitted, the median $M_{\mathrm{VT}} / L_{T}$ reduces to 111 . The median $M_{\mathrm{VT}} / L_{T}$ of all TG groups combined is 33 . When groups near the edges of the survey area are omitted, the median $M_{\mathrm{VT}} / L_{T}$ increases to 38. The median $M_{\mathrm{VT}} / L_{T}$ of the STV groups within the TG survey area, however, is 92 . This difference is caused by problems in defining groups. The STV Leo cluster (deV $9+11)$ and Coma I group (deV 13) are resolved into five smaller groups by the Turner-Gott procedure. Omitting these groups, we find that the remaining STV and TG groups in the TG survey area each have a median $M_{\mathrm{VT}} / L_{T}=70$. Of the seven groups actually common to both samples, the STV and TG mass-to-light ratios are usually identical within a factor of 2 (Tables 1 and 2), but can be that uncertain because of the sampling uncertainties.

In view of this ambiguity concerning the definition of groups, we can only conclude that the median $M_{\mathrm{VT}} / L_{T}$ of groups lies in the range $40-120$ solar units. By comparison, the integrated (Brandt) mass-to-light ratio of spiral galaxies derived from measurements of their internal motions is about 10 solar units (Dickel and Rood 1978). This discrepancy clearly is not caused by uncertainties in the mean errors of the radialvelocity measurements. The median value of the fractional uncertainty in the virial mass of a group due to radial-velocity uncertainties is $\sigma\left(V^{2}\right) / V^{2}=0.21$ for STV groups and 0.26 for TG groups. These values are derived from the cataloged mean errors, but even if the actual mean errors were $50 \%$ larger (see Dickel

TABLE 3

Median Mass-to-Light Ratios of STV and TG Groups

\begin{tabular}{|c|c|c|c|}
\hline Sample & $\begin{array}{l}\left(\frac{M_{\mathrm{VT}}}{L_{T}}\right)_{\text {median }} \\
\quad \text { solar }\end{array}$ & $\begin{array}{l}10\left\langle\frac{M V T}{L}\right\rangle \\
\quad \text { solar }\end{array}$ & $\begin{array}{l}\text { Number } \\
\text { in } \\
\text { Sample }\end{array}$ \\
\hline 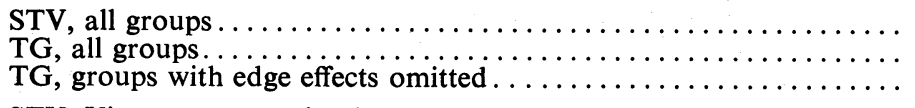 & $\begin{array}{r}127 \\
33 \\
38\end{array}$ & $\begin{array}{r}129(+32,-27) \\
34(+15,-10) \\
44(+21,-14)\end{array}$ & $\begin{array}{l}63 \\
29 \\
24\end{array}$ \\
\hline $\begin{array}{l}\text { STV, Virgo groups omitted } \ldots \ldots \ldots \ldots \ldots \ldots \ldots \ldots \ldots \ldots \ldots \ldots \ldots \ldots \\
\text { STV, Virgo and } \delta<0^{\circ}, b<0^{\circ} \text { groups omitted } \ldots \ldots \ldots \ldots \ldots \ldots \ldots\end{array}$ & $\begin{array}{r}111 \\
92\end{array}$ & $\begin{array}{r}112(+32,-24) \\
65(+36,-23)\end{array}$ & $\begin{array}{l}55 \\
22\end{array}$ \\
\hline 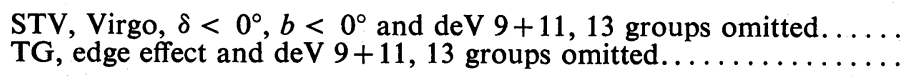 & $\begin{array}{l}72 \\
65\end{array}$ & $\begin{array}{l}59(+36,-23) \\
52(+30,-19)\end{array}$ & $\begin{array}{l}20 \\
19\end{array}$ \\
\hline
\end{tabular}



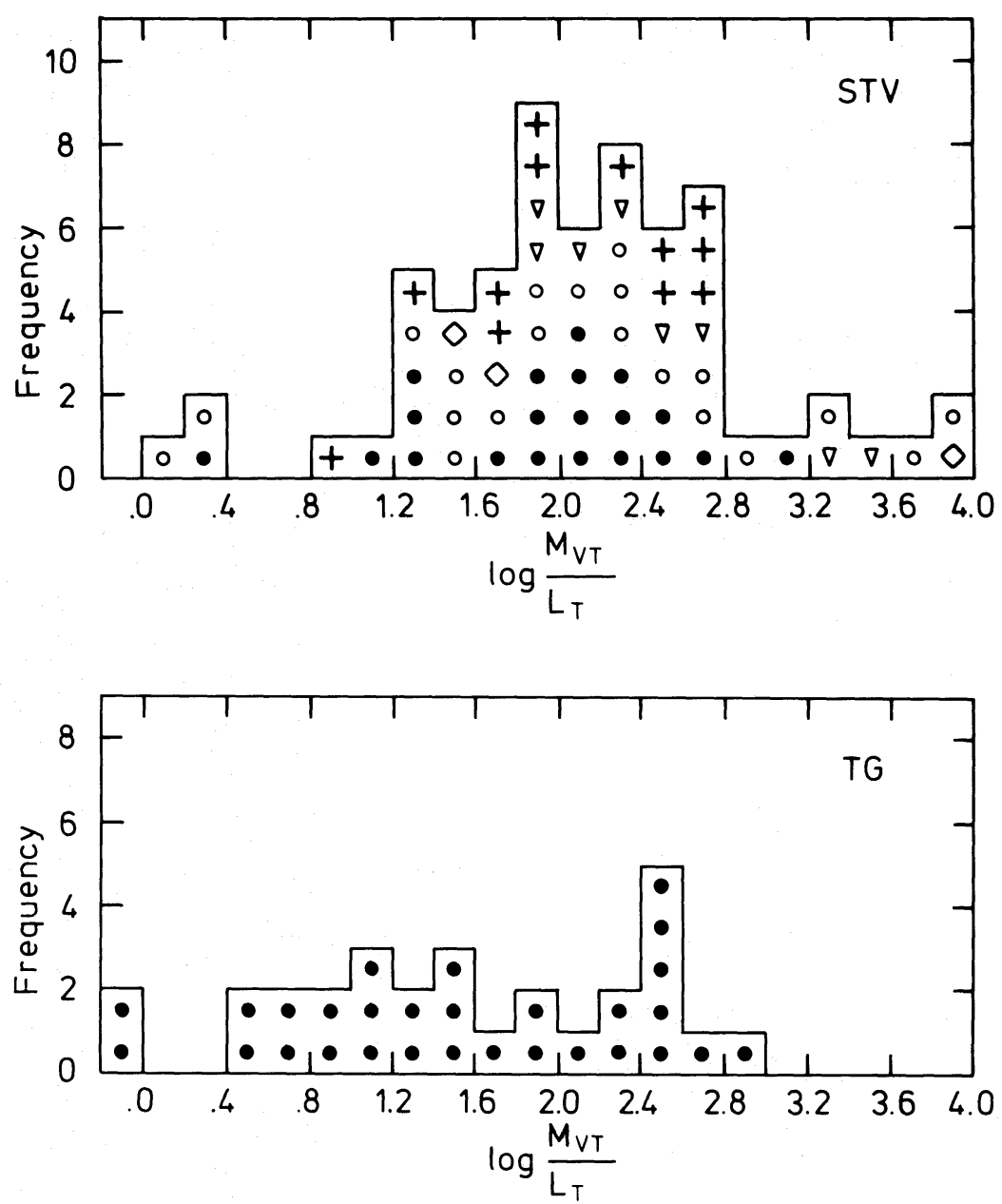

FIG. 1.-(a) Frequency distribution of logarithms of the mass-to-light ratios for STV groups. Solid circles represent groups listed by Sandage and Tammann (1975); open circles, open triangles (Virgo groups), and open diamonds (Ursa Major groups) represent additional groups listed by de Vaucouleurs (1975); crosses represent southern groups listed by Sandage (1975). (b) Frequency distribution for TG groups (Turner and Gott 1976a).

and Rood 1978), the median uncertainty would be only a factor of 2.2 larger. If the values of $M_{\mathrm{VT}} / L_{T}$ of groups were caused by underestimating the errors in radial velocities, we would expect that the groups with the largest $\sigma\left(V^{2}\right) / V^{2}$ (such that the true $\sigma_{V}$ was larger than $V$ ) should tend to have the largest values of $M_{\mathrm{VT}} / L_{T}$. But just the opposite is observed (Fig. 2)! Groups with the largest $\sigma\left(V^{2}\right) / V^{2}$ tend to have the smallest $M_{\mathrm{VT}} / L_{T}$. This is expected if the mean errors of the radial velocities are correct as represented and independent of the velocities themselves.

Our quantitative results derived from the standard virial analysis of individual groups can be compared with the results of Geller and Peebles (1973), who applied their statistical virial theorem to the galaxies cataloged by de Vaucouleurs and de Vaucouleurs (1964) which are brighter than 13th magnitude, are outside the Virgo region, and have Galactic latitude $b \geq 40^{\circ}$.

Geller and Peebles (1973) found that groups have
$M_{\mathrm{vT}} / L_{\mathrm{pg}} \approx 300$ solar units for $H=100 \mathrm{~km} \mathrm{~s}^{-1}$ $\mathrm{Mpc}^{-1}$, but conversion to $H=50 \mathrm{~km} \mathrm{~s}^{-1} \mathrm{Mpc}^{-1}$ yields $M_{\mathrm{vT}} / L_{\mathrm{pg}} \approx 150$. There are also other differences and omissions in their analysis which need modification before comparison with our results. (1) The mean luminosity used by Geller and Peebles was derived from $B(0)$ magnitudes in the catalog of de Vaucouleurs and de Vaucouleurs (1964), which are fainter than Holmberg magnitudes. Applying the transformation relations between $B(0)$ and Holmberg magnitude in Table 3 of Dickel and Rood (1978) for a typical magnitude of $B(0)=12$, we find an average correction of about $0.35 \mathrm{mag}$. (2) The luminosity must also be corrected for Galactic extinction. The Galactic extinction correction is $0.22 \mathrm{mag} \csc \langle b\rangle$, where $\langle b\rangle$ is an appropriate average Galactic latitude of the sample galaxies. We adopt $\langle b\rangle=55^{\circ} .2$, which approximately divides the sampled area of the sky into two equal parts. (3) Correction for internal extinction within each observed galaxy is roughly $0.2 \mathrm{mag} \csc \langle i\rangle$, and 

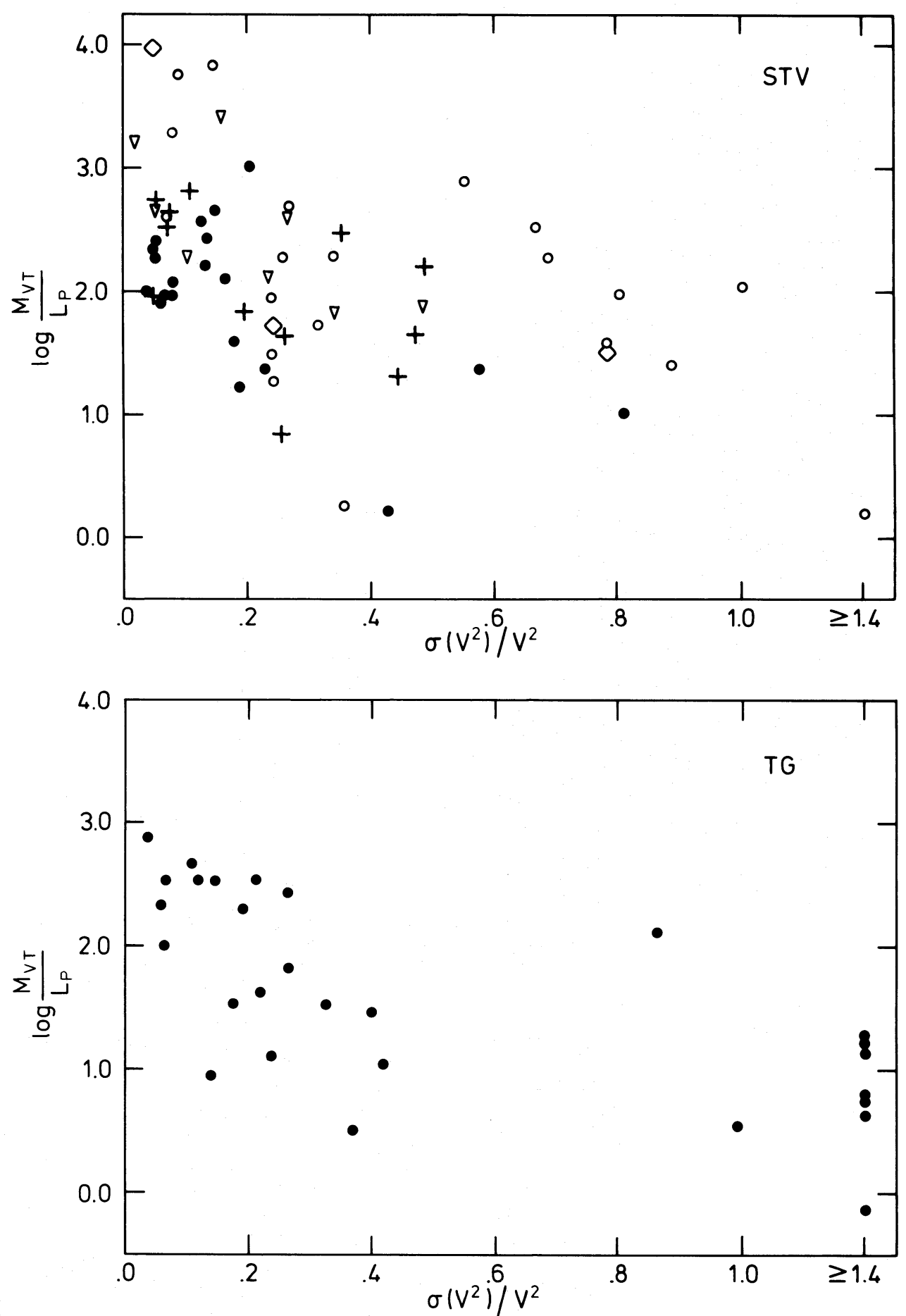

Fig. 2.- Logarithm of virial mass-to-light ratio versus fractional uncertainty in virial mass caused by random errors in radial velocity measurements, for $(a)$ STV groups and $(b)$ TG groups. Symbols are explained in the legend to Fig. 1.

we adopt $\langle i\rangle=60^{\circ}$. The total correction is thus 0.35 (magnitude conversion) +0.27 (Galactic extinction) + 0.40 (internal extinction) $=1.02 \mathrm{mag}$. The GellerPeebles value of $M_{\mathrm{vT}} / L_{\mathrm{pg}}$ must therefore be reduced by a factor of 2.5 , yielding $M_{\mathrm{VT}} / L_{\mathrm{pg}} \approx 60$. Finally, if a mean factor of 1.35 were applied to convert from observed luminosities to total group luminosities, the Geller-Peebles value would be reduced to $M_{\mathrm{vT}} / L_{T} \approx$ 45 , in agreement with the median value for the TG groups. 


\section{b) Crossing Times}

As originally suggested by Turner and Sargent (1974), crossing times can be used to indicate whether a group is bound or expanding. Frequency distributions of $\log \left(t_{c} H\right)$ are presented in Figure 3. The median crossing times are $0.2 \mathrm{H}^{-1}$ (STV groups) and $0.1 H^{-1}$ (TG groups). The fractional uncertainty in a crossing time caused by random errors in radial velocities is approximately $\sigma\left(V^{2}\right) / 2 V^{2}$; the median fractional uncertainty is about $12 \%$. The crossing times of all but one of the STV and TG groups are less than $H^{-1}$, which indicates that all of the groups are bound-none are chance concentrations of nearest-neighbor galaxies individually expanding away from each other in the Hubble flow. Jackson (1975) earlier showed that the "moment of inertia" crossing times of the groups listed by de Vaucouleurs (1975) are less than $H^{-1}$.
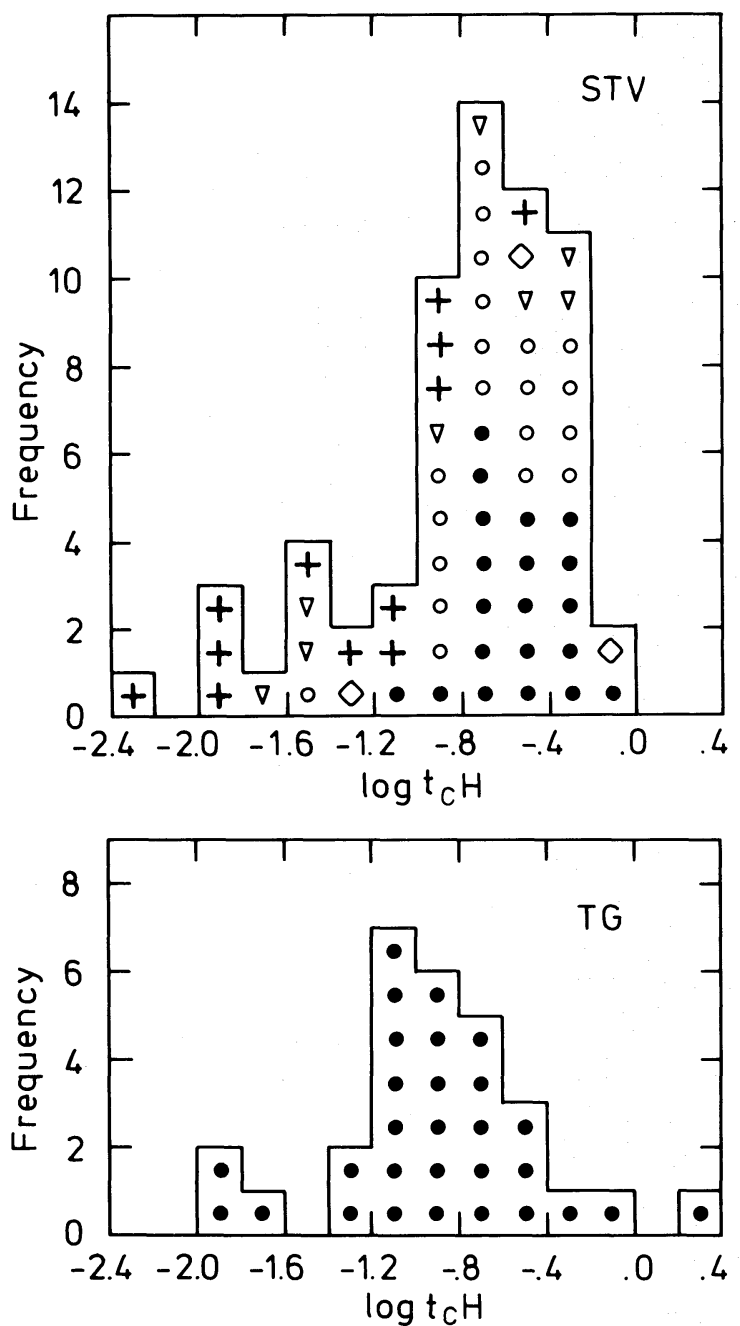

FIG. 3.-Frequency distribution of the logarithms of the crossing time, $t_{c}=\langle r\rangle \mid\langle v\rangle$, in units of the Hubble time, for (a) STV groups and (b) TG groups. Symbols are explained in the legend to Fig. 1.
Geller and Peebles (1973) found that the angular positions and radial velocities of pairs of galaxies with angular separations $\theta_{c} \leq 6^{\circ}$ are strongly correlated-the number of pairs with small velocity difference is greatly in excess of the number predicted if the pairs were all chance superpositions of unrelated galaxies. These pairs with $\theta_{c} \leq 6^{\circ}$ and small velocity differences were assumed to be group members. The average time for two galaxies in this sample to move a distance equal to their separation, i.e., the average crossing time, is approximately

$$
t_{c}=\frac{\frac{4}{\pi}\left(\theta_{c} / 2\right) d}{3^{1 / 2}\left\langle V_{i j}{ }^{2}\right\rangle^{1 / 2}},
$$

where $\theta_{c} / 2$ is the approximate average angular separation of the members of a pair, $d$ is the average distance to a pair, $4 / \pi$ converts the projected average separation to its three-dimensional value, and $3^{1 / 2}$ converts the radial-velocity dispersion to space-velocity dispersion.

Geller and Peebles evaluated the root-mean-square radial velocity difference of this sample of pairs, $\left\langle V_{i j}{ }^{2}\right\rangle^{1 / 2}=245 \mathrm{~km} \mathrm{~s}^{-1}$ (corrected for random errors in radial velocities, spurious radial velocities, and optical pairs). We note that this is close to the value of $270 \mathrm{~km} \mathrm{~s}^{-1}$ found for the virial velocity dispersion, $V$, for the STV and TG groups (Table 5 below). Then, adopting $d=25 \mathrm{Mpc}$, the median distance of the de Vaucouleurs groups, we find $t_{c}=0.2 H^{-1}$, which is consistent with the crossing times obtained above for the STV and TG groups.

Frequency distributions of $\log \left(t_{\mathrm{vT}} H\right)$ for the STV and TG groups are presented in Figure 4. The histogram for STV groups is single-peaked, not doublepeaked as indicated in earlier work (Turner and Sargent 1974; Gott et al. 1974). This revision is evidently caused primarily by the use of more accurate and extensive radial-velocity data in the present work.

\section{c) Virial Correlations}

Various correlations among particular properties of groups have been previously suggested in the literature. To check and refine these results, we have performed regression-line analyses and significance tests on the data in the present study. Our results are summarized in Table 4. These analyses were performed for the 44 (of 63) STV groups outside the Virgo region with $\sigma\left(V^{2}\right) / V^{2}<0.5$, and for the 19 (of 29) TG groups with $\sigma\left(V^{2}\right) / V^{2}<0.5$. Heeding the advice of Materne and Tammann (1974), we discard the groups with $\sigma\left(V^{2}\right) / V^{2} \geq 0.5$ from further analysis although we note that the results do not change when the noisier samples are included. The samples of STV and TG groups analyzed are therefore subsets of the totality of STV groups and basic published TG groups (Turner and Gott 1976a). Some correlations claimed in the literature, e.g., between $M_{\mathrm{VT}} / L_{T}$ and $L_{T}$, $M_{\mathrm{vT}} / L_{T}$ and $d_{\mathrm{cm}}, M_{\mathrm{vT}} / L_{T}$ and $f_{s}, L_{T}$ and $R$, are not statistically significant. The TG groups show a correlation between $\langle v\rangle$ and $\langle r\rangle$ but the STV groups do not. $V$ and $R$ are uncorrelated in both samples. 

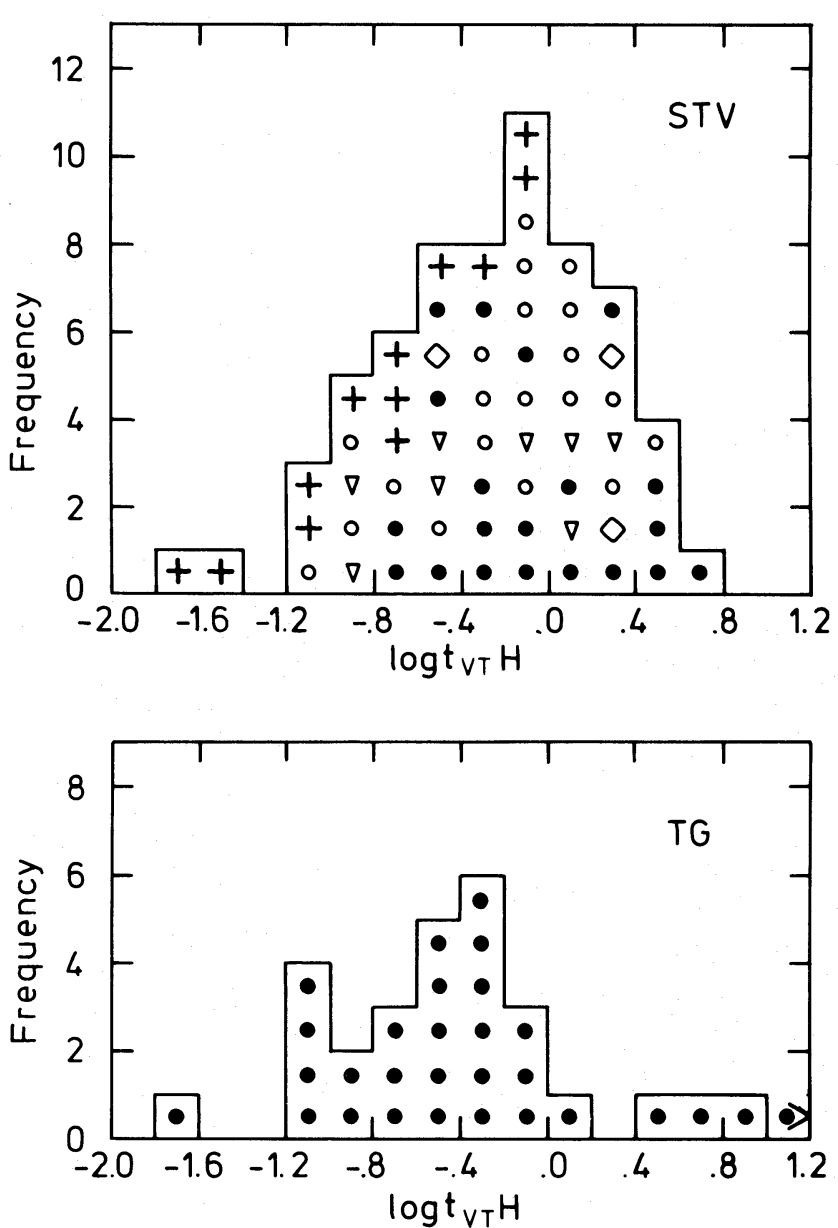

FIG. 4.-Frequency distribution of the logarithms of the virial crossing time, $t_{\mathrm{VT}}=R / V$, in units of the Hubble time, for (a) STV groups and (b) TG groups. Symbols are explained in the legend to Fig. 1.

$M_{\mathrm{VT}} / L_{T}$ is correlated with $R\left(M_{\mathrm{VT}} / L_{T} \approx R\right)$ and even more strongly with $V\left(M_{\mathrm{VT}} / L_{T} \approx V^{1.6}\right)$. We will call these two correlations the "virial correlations." Plots of $M_{\mathrm{VT}} / L_{T}$ versus $V, M_{\mathrm{VT}} / L_{T}$ versus $R$, and $V$ versus $R$ for the STV and TG groups are presented in Figures 5-7. The virial correlations and the independence of $V$ upon $R$ were found previously by Rood et al. (1970) with poorer data and analytical techniques.

The basic question which we now attempt to answer is, Are the virial correlations intrinsic (i.e., cosmic) properties of groups, or are they artificially produced by observational and statistical uncertainties in the analysis?

Aarseth and Saslaw (1972) have listed the uncertainties besetting the calculation of virial parameters: (a) the availability of data for only a subset of galaxies in each group (in our study, we assume that this subset, composed of the brighter group members, is a representative sample); $(b)$ the application of statistical average corrections for the projection of separations onto the celestial sphere and space velocity onto the line of sight (projection effect); (c) the measurement of instantaneous values of position and velocity rather than time averages (quasi-equilibrium effect); $(d)$ errors in the masses of individual galaxies; $(e)$ errors in radial velocities; $(f)$ errors in total luminosities of the galaxies and the groups (we neglect this uncertainty because the galactic luminosities are usually known to photoelectric accuracy and most of the luminosity of a group is contained in the observed galaxies, so that extrapolation errors are small; also, luminosity errors are probably uncorrelated with $V$ and $R) ;(g)$ uncertainties in deciding group membership (this important problem is outside the scope of our study, and we assume that the STV and TG groups are real and uncontaminated groups); $(h)$ errors in distances. A change in the Hubble constant cannot induce correlations, because it would change $M_{\mathrm{VT}} / L_{T}$ (and $R$ ) for all groups by the same factor. The random uncertainty in the distance due to the deviation of the centroid velocity from the Hubble flow and virial uncertainties (Sandage and Tammann 1975) is typically a few percent for the STV and TG groups. Random errors in distances would not induce a correlation between $M_{\mathrm{VT}} / L_{T}$ and $V$ and they would induce an $M_{\mathrm{VT}}$ versus $R$ correlation 
TABLE 4

Regression-Line Coefficients for STV and TG SAMPLeS*

\begin{tabular}{|c|c|c|c|c|c|c|c|c|c|c|c|}
\hline Sample & $y$ & $x$ & $a_{1}$ & $S_{1}$ & $a_{0}$ & $S_{0}$ & $r$ & $N$ & $Z_{0}$ & $\begin{aligned} P & \geq 95 \% \\
\left(z_{0}\right. & \geq 1.96)\end{aligned}$ & $\begin{aligned} P & \geq 99 \% \\
\left(z_{0}\right. & \geq 2.58)\end{aligned}$ \\
\hline $\begin{array}{l}\text { STV } \\
\text { TG }\end{array}$ & $\begin{array}{l}V \\
V\end{array}$ & $\begin{array}{l}R \\
R\end{array}$ & $\begin{array}{l}+0.20 \\
+0.11\end{array}$ & $\begin{array}{l}0.12 \\
0.18\end{array}$ & $\begin{array}{l}+2.36 \\
+2.43\end{array}$ & $\begin{array}{l}0.07 \\
0.08\end{array}$ & $\begin{array}{l}+0.25 \\
+0.14\end{array}$ & $\begin{array}{l}44 \\
19\end{array}$ & $\begin{array}{l}+1.64 \\
+0.56\end{array}$ & & \\
\hline $\begin{array}{l}\text { STV } \\
\text { TG }\end{array}$ & $\begin{array}{l}\langle v\rangle \\
\langle v\rangle\end{array}$ & $\begin{array}{l}\langle r\rangle \\
\langle r\rangle\end{array}$ & $\begin{array}{l}+0.20 \\
+0.25\end{array}$ & $\begin{array}{l}0.13 \\
0.11\end{array}$ & $\begin{array}{l}+2.51 \\
+2.54\end{array}$ & $\begin{array}{l}0.05 \\
0.06\end{array}$ & $\begin{array}{l}+0.23 \\
+0.48\end{array}$ & $\begin{array}{l}44 \\
19\end{array}$ & $\begin{array}{l}+1.50 \\
+2.09\end{array}$ & $x$ & \\
\hline $\begin{array}{l}\text { STV } \\
\text { TG }\end{array}$ & $\begin{array}{l}M_{\mathrm{VT}} / L_{T} \\
M_{\mathrm{VT}} / L_{T}\end{array}$ & $\begin{array}{l}R \\
R\end{array}$ & $\begin{array}{l}+1.30 \\
+0.76\end{array}$ & $\begin{array}{l}0.20 \\
0.35\end{array}$ & $\begin{array}{l}+1.65 \\
+1.83\end{array}$ & $\begin{array}{l}0.11 \\
0.15\end{array}$ & $\begin{array}{l}+0.71 \\
+0.46\end{array}$ & $\begin{array}{l}44 \\
19\end{array}$ & $\begin{array}{l}+5.68 \\
+1.99\end{array}$ & $\begin{array}{l}x \\
x\end{array}$ & $x$ \\
\hline $\begin{array}{l}\text { STV } \\
\text { TG }\end{array}$ & $\begin{array}{l}M_{\mathrm{VT}} / L_{T} \\
M_{\mathrm{VT}} / L_{T}\end{array}$ & $\begin{array}{l}V \\
V\end{array}$ & $\begin{array}{l}+1.70 \\
+1.61\end{array}$ & $\begin{array}{l}0.24 \\
0.36\end{array}$ & $\begin{array}{l}-1.99 \\
-2.03\end{array}$ & $\begin{array}{l}0.60 \\
0.88\end{array}$ & $\begin{array}{l}+0.73 \\
+0.74\end{array}$ & $\begin{array}{l}44 \\
19\end{array}$ & $\begin{array}{l}+5.95 \\
+3.80\end{array}$ & $\begin{array}{l}x \\
x\end{array}$ & $\begin{array}{l}x \\
x\end{array}$ \\
\hline $\begin{array}{l}\text { STV } \\
\text { TG }\end{array}$ & $\begin{array}{l}M_{\mathrm{VT}} / L_{T} \\
M_{\mathrm{VT}} / L_{T}\end{array}$ & $\begin{array}{l}L_{T} \\
L_{T}\end{array}$ & $\begin{array}{l}+0.09 \\
-0.10\end{array}$ & $\begin{array}{l}0.32 \\
0.36\end{array}$ & $\begin{array}{l}+2.00 \\
+2.05\end{array}$ & $\begin{array}{l}0.48 \\
0.54\end{array}$ & $\begin{array}{l}+0.04 \\
-0.07\end{array}$ & $\begin{array}{l}44 \\
19\end{array}$ & $\begin{array}{l}+0.26 \\
-0.28\end{array}$ & & \\
\hline $\begin{array}{l}\text { STV } \\
\text { TG }\end{array}$ & $\begin{array}{l}M_{\mathrm{VT}} / L_{T} \\
M_{\mathrm{VT}} / L_{T}\end{array}$ & $\begin{array}{l}d_{\mathrm{cm}} \\
d_{\mathrm{cm}}\end{array}$ & $\begin{array}{l}+0.07 \\
+0.05\end{array}$ & $\begin{array}{l}0.38 \\
0.51\end{array}$ & $\begin{array}{l}+2.04 \\
+1.84\end{array}$ & $\begin{array}{l}0.56 \\
0.75\end{array}$ & $\begin{array}{l}+0.03 \\
+0.02\end{array}$ & $\begin{array}{l}44 \\
19\end{array}$ & $\begin{array}{l}+0.19 \\
+0.08\end{array}$ & & \\
\hline $\begin{array}{l}\text { STV } \\
\text { TG }\end{array}$ & $\begin{array}{l}M_{\mathrm{VT} /} / L_{T} \\
M_{\mathrm{VT}} / L_{T}\end{array}$ & $\begin{array}{l}t_{c} H \\
t_{c} H\end{array}$ & $\begin{array}{l}-0.14 \\
-0.38\end{array}$ & $\begin{array}{l}0.26 \\
0.36\end{array}$ & $\begin{array}{l}+2.02 \\
+1.51\end{array}$ & $\begin{array}{l}0.25 \\
0.40\end{array}$ & $\begin{array}{l}-0.09 \\
-0.25\end{array}$ & $\begin{array}{l}44 \\
19\end{array}$ & $\begin{array}{l}-0.58 \\
-1.02\end{array}$ & & \\
\hline $\begin{array}{l}\text { STV } \\
\text { TG }\end{array}$ & $\begin{array}{l}M_{\mathrm{VT} /} / L_{T} \\
M_{\mathrm{VT}} / L_{T}\end{array}$ & $\begin{array}{l}10^{f_{s}} \\
10^{f_{s}}\end{array}$ & $\begin{array}{r}0.00 \\
-1.30\end{array}$ & $\begin{array}{l}0.33 \\
0.54\end{array}$ & $\begin{array}{l}+2.14 \\
+2.85\end{array}$ & $\begin{array}{l}0.23 \\
0.42\end{array}$ & $\begin{array}{r}0.00 \\
-0.50\end{array}$ & $\begin{array}{l}44 \\
19\end{array}$ & $\begin{array}{r}0.00 \\
-2.20\end{array}$ & $x$ & \\
\hline $\begin{array}{l}\text { STV } \\
\text { TG }\end{array}$ & $\begin{array}{l}t_{c} H \\
t_{c} H\end{array}$ & $\begin{array}{l}10^{f_{s}} \\
10^{f_{s}}\end{array}$ & $\begin{array}{l}+0.64 \\
+0.10\end{array}$ & $\begin{array}{l}0.17 \\
0.41\end{array}$ & $\begin{array}{l}-1.22 \\
-1.09\end{array}$ & $\begin{array}{l}0.12 \\
0.32\end{array}$ & $\begin{array}{l}+0.49 \\
+0.06\end{array}$ & $\begin{array}{l}44 \\
19\end{array}$ & $\begin{array}{l}+3.43 \\
+0.24\end{array}$ & $x$ & $x$ \\
\hline $\begin{array}{l}\text { STV } \\
\text { TG }\end{array}$ & $\begin{array}{l}L_{T} \\
L_{T}\end{array}$ & $\begin{array}{l}R \\
R\end{array}$ & $\begin{array}{l}+0.09 \\
+0.46\end{array}$ & $\begin{array}{l}0.14 \\
0.25\end{array}$ & $\begin{array}{l}+1.43 \\
+1.40\end{array}$ & $\begin{array}{l}0.08 \\
0.10\end{array}$ & $\begin{array}{l}+0.11 \\
+0.41\end{array}$ & $\begin{array}{l}44 \\
19\end{array}$ & $\begin{array}{r}+0.71 \\
1.74\end{array}$ & & \\
\hline $\begin{array}{l}\text { STV } \\
\text { TG }\end{array}$ & $\begin{array}{l}L_{T} \\
L_{T}\end{array}$ & $\begin{array}{l}\langle r\rangle \\
\langle r\rangle\end{array}$ & $\begin{array}{l}+0.39 \\
+0.80\end{array}$ & $\begin{array}{l}0.13 \\
0.10\end{array}$ & $\begin{array}{l}+1.48 \\
+1.63\end{array}$ & $\begin{array}{l}0.05 \\
0.06\end{array}$ & $\begin{array}{l}+0.42 \\
+0.89\end{array}$ & $\begin{array}{l}44 \\
19\end{array}$ & $\begin{array}{l}2.87 \\
5.69\end{array}$ & $\begin{array}{l}x \\
x\end{array}$ & $\begin{array}{l}x \\
x\end{array}$ \\
\hline
\end{tabular}

${ }^{*} \log y=\left(a_{0} \pm S_{0}\right)+\left(a_{1} \pm S_{1}\right) \log x$.

NoTES. $-r=$ observed correlation coefficient. $N=$ number in sample. $Z_{0}=$ the $Z$-statistic (Hogg and Craig 1970; Freund 1971 ) for testing if $r$ could come from a population with a zero correlation coefficient. If $Z_{0} \geq 1.96$, this hypothesis can be rejected with $\geq 95 \%$ confidence; if $Z_{0} \geq 2.58$, the hypothesis can be rejected with $\geq 99 \%$ confidence.

in the opposite sense to that which is observed. For these reasons, we can neglect errors in distance.

Before discussing the tedious details of our analysis to determine if the virial correlations are caused by uncertainties, we first summarize our approach and results.

Initially, we select theoretical samples of groups, each with the same true mass $M$ and luminosity $L_{T}$. To account for changes in the observed properties resulting from projection and quasi-equilibrium effects, we apply results of Newtonian $N$-body experiments (kindly provided by Dr. E. L. Turner) to derive values of $M_{\mathrm{VT}} / L_{T}, V / V_{A}$, and $R / R_{A}$, where $V_{A}$ and $R_{A}$ are the actual (i.e., cosmic) virial velocity dispersion and radius of a group. We then statistically apply errors in galactic masses and radial velocities. The sizes of the applied errors are chosen to be the same as observed errors for the STV and TG groups. The ranges of the resulting theoretical values of $M_{\mathrm{VT}} / L_{T}, V / V_{A}$, and $R / R_{A}$ are found to be much smaller than the observed ranges of $M_{\mathrm{VT}} / L_{T}, V$, and $R$ for the STV and TG groups. Hence, our first conclusion is that the $o b$ served ranges in $M_{\mathrm{VT}} / L_{T}, V$, and $R$ are larger than the ranges produced by the effects of projection, quasiequilibrium, errors in galactic mass, and errors in radial velocity. If difficulties in identifying actual groups and distinguishing members from nonmembers are not of dominant importance, then the difference between the observed and theoretical ranges is caused by ranges in the intrinsic parameters $M / L_{T}, V_{A}$, and $R_{A}$. We are thus forced to drop our initial assumption that all groups have the same $M / L_{T}$. We then let the theoretical groups take on a range of uncorrelated values of $M / L_{T}, V_{A}$, and $R_{A}$, chosen so that the ranges in $M_{\mathrm{VT}} / L_{T}, V$, and $R$ of these theoretical samples become identical to those observed for the STV and TG samples. The theoretical samples therefore become realistic in that they include appropriate ranges of intrinsic parameters, as well as the effects of projection, quasi-equilibrium, galaxy mass errors, and radial velocity errors. We find, however, that the STV and TG samples show a significantly stronger correlation between $M_{\mathrm{VT}} / L_{T}$ and $V$ than that exhibited by the theoretical samples. Since the various uncertainties in the theoretical and observed samples have been made the same, we are forced to conclude that whereas $M_{\mathrm{VT}} / L_{T}$ and $V_{A}$ are uncorrelated in the theoretical samples, they are correlated in the observed samples, unless difficulties in identifying actual groups and distinguishing members from nonmembers are much more important than is generally believed.

We now describe the tedious details. Because the various uncertainties are statistically independent, the virial parameters of a group can be expressed in the form

$$
\begin{aligned}
\log \frac{M_{\mathrm{VT}}}{L_{T}}= & \log \frac{M}{L_{T}}+\left(\Delta \log \frac{M_{\mathrm{VT}}}{M}\right)_{\mathrm{pe}} \\
& +\left(\Delta \log \frac{M_{\mathrm{VT}}}{L_{T}}\right)_{\mathrm{m}}+\left(\Delta \log \frac{M_{\mathrm{VT}}}{L_{T}}\right)_{\mathrm{v}},
\end{aligned}
$$

$\log V=\log V_{A}+(\Delta \log V)_{\mathrm{pe}}$

$$
+(\Delta \log V)_{\mathrm{m}}+(\Delta \log V)_{\mathrm{v}},
$$



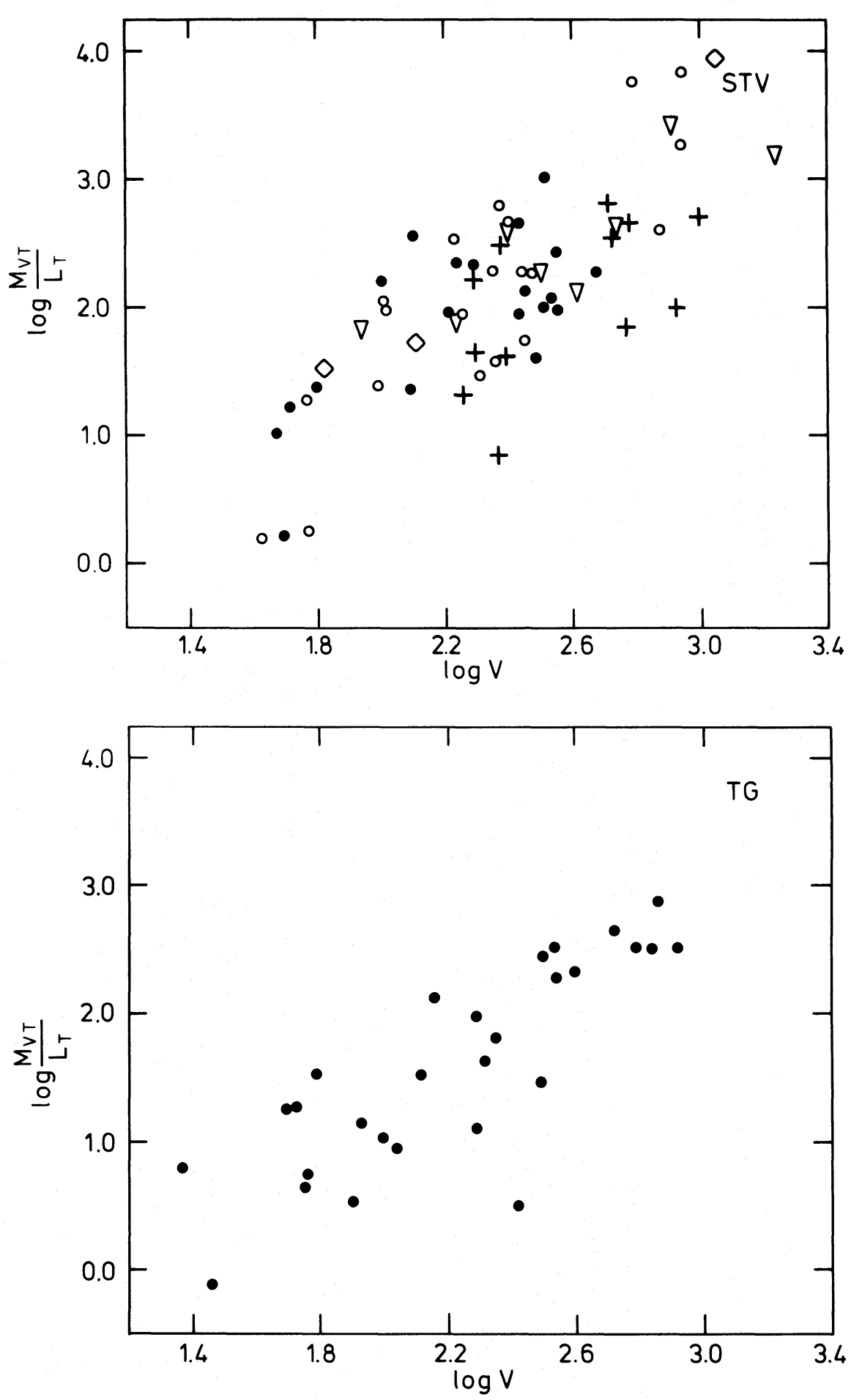

FIG. 5.-Logarithm of the virial mass-to-light ratio versus logarithm of the virial velocity dispersion, for (a) STV groups and (b) TG groups. Symbols are explained in the legend to Fig. 1. 

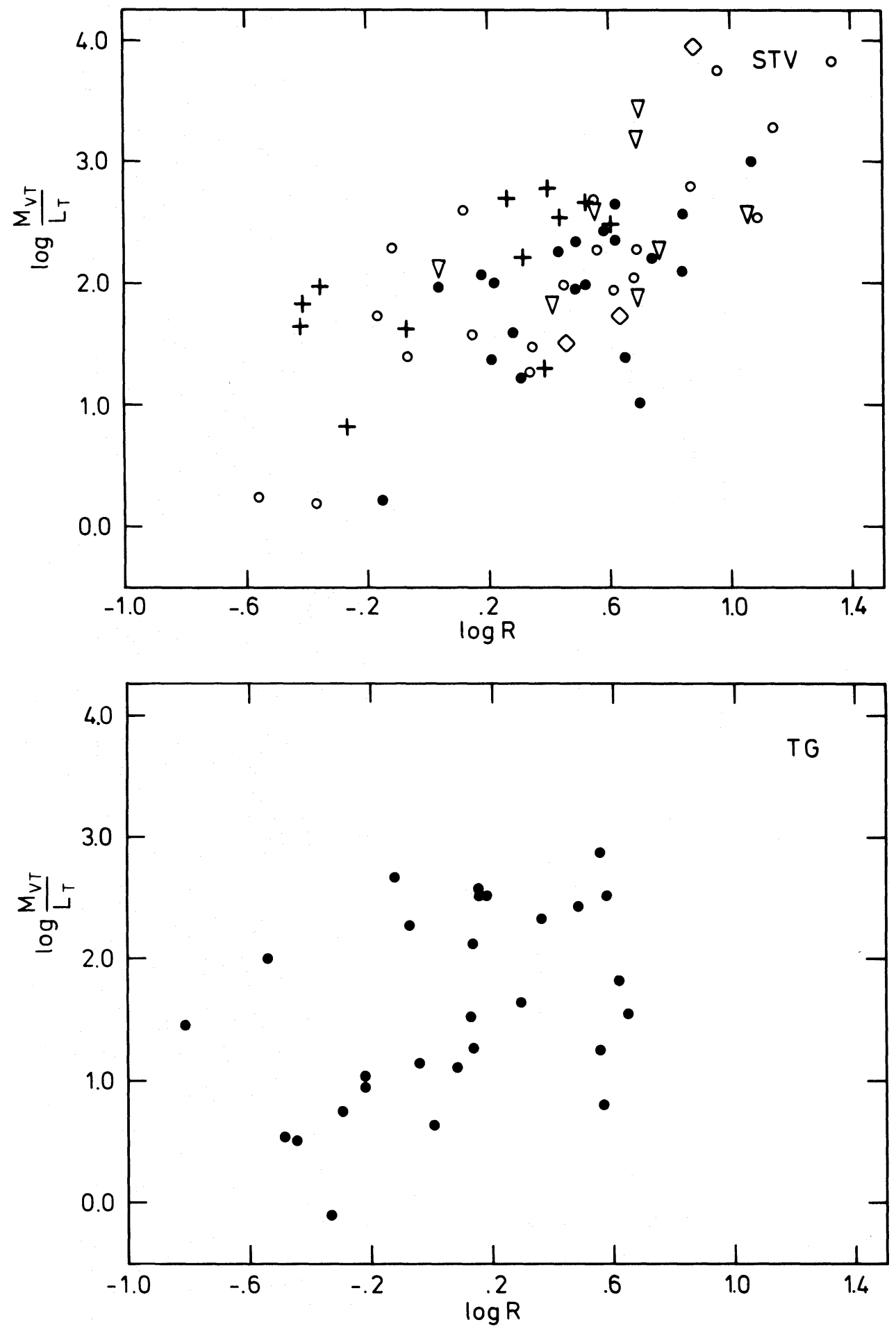

FIG. 6.- - Logarithm of the virial mass-to-light ratio versus logarithm of the virial radius, for (a) STV groups and (b) TG groups. Symbols are explained in the legend to Fig. 1. 

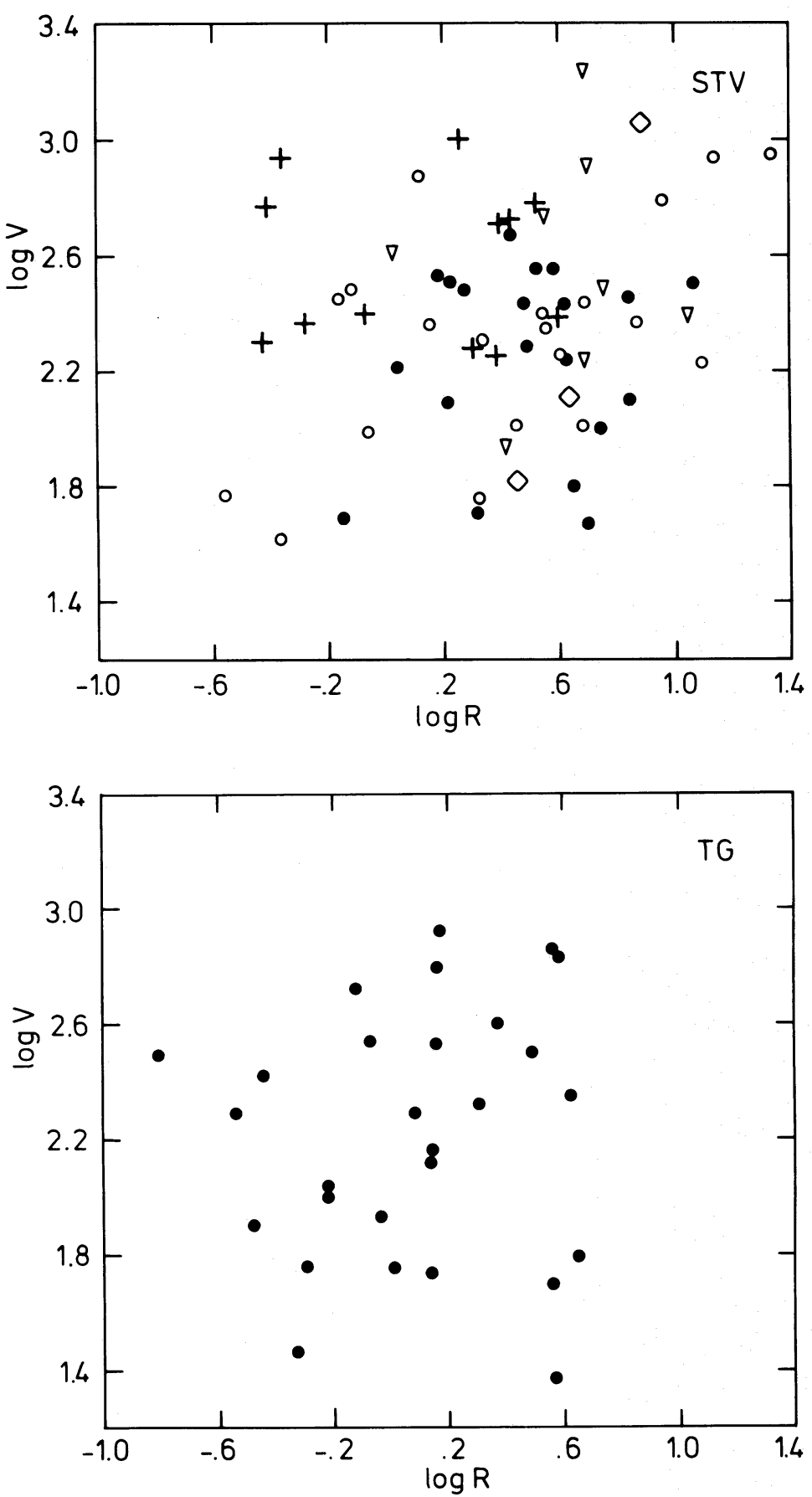

FIG. 7.- Logarithm of the virial velocity dispersion versus logarithm of the virial radius, for (a) STV groups and (b) TG groups. Symbols are explained in the legend to Fig. 1.

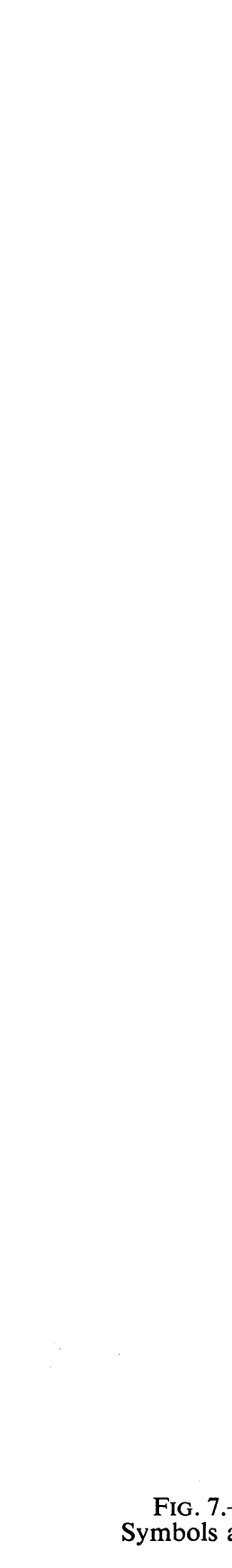

$\log R=\log R_{A}+(\Delta \log R)_{\mathrm{pe}}$ $+(\Delta \log R)_{\mathrm{m}}+(\Delta \log R)_{\mathrm{v}}$

or more generally,

$$
\begin{aligned}
\log x= & (\log x)_{A}+(\Delta \log x)_{\mathrm{pe}} \\
& +(\Delta \log x)_{\mathrm{m}}+(\Delta \log x)_{\mathrm{v}}
\end{aligned}
$$

where $(\Delta \log x)_{\mathrm{pe}},(\Delta \log x)_{\mathrm{m}}$, and $(\Delta \log x)_{\mathrm{v}}$ are the changes in the virial parameters caused by projection and quasi-equilibrium effects, galactic mass errors, and radial velocity errors, respectively.

Our task is to select values of the parameters on the right-hand-side of equations (4)-(6) for the groups in the theoretical samples. Values of $(\Delta \log x)_{\text {pe }}$, 
( $x=M_{\mathrm{vT}} / M, V$, and $R$ ) have been taken from the results of $N$-body computer simulations by Turner. Turner performed the Newtonian $N$-body experiments on groups with six bodies having masses $(3,1,1,1,1,1)$ and negative total energies. These groups were set to expand initially but soon collapsed, relaxed, and reached virial equilibrium. The radial velocities and projected separations of group members were evaluated at random times from three random orthogonal directions. From Turner's data, 151 independent determinations of $(\log x)_{\text {pe }}$ were derived. A histogram of the values of $\left(\log M_{\mathrm{VT}} / M\right)_{\mathrm{pe}}$ is shown in Figure 3 of Gott and Turner (1977). From the 151 determinations, a random selection of $(\Delta \log x)_{\mathrm{pe}}$ for each theoretical sample was made by means of a table of random numbers. Because we wish to prevent the situation whereby a result obtained for a theoretical sample is actually due to a statistical fluke (i.e., occurrence of small probability), we did the analysis on three independent theoretical samples $(\mathrm{A}, \mathrm{B}, \mathrm{C})$ of 44 groups corresponding to the 44 STV groups, and three independent theoretical samples (D, E, F) of 19 groups corresponding to the 19 TG groups.

For $(\Delta \log x)_{\mathrm{m}}$ and $(\Delta \log x)_{\mathrm{v}}$, we need to assure that the absolute values applied to our theoretical samples are the same as those contained in the observed STV and TG samples. This is done by assigning one STV group to each model group in sets A, B, and $C$ and one TG group to each group in sets $D, E$, and $\mathrm{F}$, and then simply applying the values of $\left|(\Delta \log x)_{\mathrm{m}}\right|$ and $\left|(\Delta \log x)_{\mathrm{v}}\right|$ for the (44 or 19) observed groups to the (44 or 19) theoretical groups in each sample, where for each group in each sample, the sign of the deviation [e.g., $(\Delta \log x)_{\mathrm{m}}=+\left|(\Delta \log x)_{\mathrm{m}}\right|$ or $\left.(\Delta \log x)_{\mathrm{m}}=-\left|(\Delta \log x)_{\mathrm{m}}\right|\right]$ is determined by a random choice.

$(\Delta \log x)_{m}$ for each observed group is approximated by the ratio of the observed $x$ (obtained with the adopted galactic masses) to the $x$ obtained when each galactic mass is increased or decreased (according to a random choice) by its average uncertainty. This uncertainty is taken to be a factor of 1.2 for galactic masses derived from detailed rotation curves, a factor of 1.4 for galactic masses derived from global halfwidths of $21 \mathrm{~cm}$ profiles, and a factor of 1.8 for galactic masses derived from luminosities (Dickel and Rood 1978). These uncertainties are similar to those adopted by Materne and Tammann (1974). The adopted factors apply if Brandt masses are realistic integrated masses or if they differ from actual integrated masses by a constant factor independent of galactic type or luminosity.

Similarly, $(\Delta \log x)_{\mathrm{v}}$ for each observed group can be approximated through the use of the calculated values of $\sigma\left(V^{2}\right) / V^{2}$ in Tables 1 and 2 . $\left[\Delta \log \left(M_{\mathrm{VT}} / L_{T}\right)\right]_{\mathrm{v}}=q \sigma\left(V^{2}\right) / V^{2},(\Delta \log V)_{\mathrm{v}}=1-$ $\left[1+q \sigma\left(V^{2}\right) / V^{2}\right]^{1 / 2}$, and $(\Delta \log R)_{\mathrm{v}}=0$. The constant $q$ is +1 or -1 according to a random choice.

Averages and standard deviations (dispersions) about the averages of $\log x,(\log x)_{\text {pe }},(\log x)_{\mathrm{m}}$, and $(\log x)_{\mathrm{v}}$ for the STV and TG groups and the theoretical groups are listed in Table 5. We notice the following: (a) $\left\langle(\log x)_{\mathrm{pe}}\right\rangle=0$, which means that the logarithmic average (or median) values of the intrinsic and observed virial parameters are about the same. This has already been pointed out by Aarseth and Saslaw (1972) and Gott and Turner (1977). (b) The dispersion in observed virial parameters caused by projection and quasi-equilibrium effects is nearly always larger than that caused by galactic mass errors, which is larger than that caused by radial velocity errors. (c) The dispersion caused by projection and quasi-equilibrium effects, galactic mass errors, and radial-velocity errors combined is only about half of that observed in the STV and TG samples. Hence, one or more additional sources of dispersion are required. If the STV and TG groups are real uncontaminated groups, then this source is a dispersion in the intrinsic virial parameters $(\log x)_{A}$, where $x=M / L_{T}, V_{A}$, and $R_{A}$, respectively.

If our theoretical groups are to have the same total dispersions in $\log x$ as the STV and TG groups, then we must incorporate into our theoretical groups a range of values of $(\log x)_{A}$ with a dispersion given by

$$
\begin{aligned}
\sigma(\log x)_{A}=[ & \sigma^{2}(\log x)-\sigma^{2}(\log x)_{\mathrm{pe}} \\
& \left.-\sigma^{2}(\log x)_{\mathrm{m}}-\sigma^{2}(\log x)_{\mathrm{v}}\right]^{1 / 2} .
\end{aligned}
$$

Each value of $(\log x)_{A}$ was randomly selected for each theoretical group from an array of values with a Gaussian probability function, a dispersion given by equation (8), and an average value $\left\langle(\log x)_{A}\right\rangle=0$. It follows that $M / L_{T}, V_{A}$, and $R_{A}$ for our theoretical samples are uncorrelated with one another, to within the uncertainties of random sampling. The normalization about zero rather than the mean values for the observed groups has no effect upon the analysis because it is the distributions of these parameters, not their means, which determine the form of any possible correlation between $M_{\mathrm{VT}} / L_{T}, V$ and $R$. The derived averages and standard deviations in $\log x$ for our theoretical samples of groups with a range in $(\log x)_{A}$ are included in Table 5.

Regression-line coefficients and correlation coefficients for plots of $V$ versus $R, M_{\mathrm{VT}} / L_{T}$ versus $V$, and $M_{\mathrm{VT}} / L_{T}$ versus $R$ for the STV, TG, and theoretical groups are presented in Table $6 . V$ is uncorrelated with $R$ in all samples. The regression of $M_{\mathrm{VT}} / L_{T}$ upon $V$ has a correlation coefficient of about 0.73 for both the STV and TG samples. Only one of the six theoretical samples has a significant nonzero correlation coefficient. The probability that a correlation coefficient as large as 0.73 for the STV groups could result from a random sampling of the theoretical groups is less than $1 \%$ ( $z$-test). The corresponding probability for the $\mathrm{TG}$ groups is $5 \%$. In Figure 8, plots of $M_{\mathrm{VT}} / L_{T}$ versus $V$ for the STV and TG groups are compared with corresponding plots for the theoretical samples. Since the STV and TG samples display a correlation between $M_{\mathrm{VT}} / L_{T}$ and $V$ which is significantly larger than that shown by the theoretical samples which have uncorrelated intrinsic virial parameters, but the various uncertainties for the observed and theoretical samples are about the same, 
TABLE 5

Average and Standard Deviation of Virial Parameters for STV, TG, and Model Group Samples

\begin{tabular}{|c|c|c|c|c|c|c|c|c|c|c|c|}
\hline Sample* & $\begin{array}{c}\text { Parameter } \\
x\end{array}$ & $\begin{array}{l}\text { Ave. } \\
\log x\end{array}$ & m.e. & $\sigma$ & m.e. & Sample† & $\begin{array}{c}\text { Parameter } \\
x\end{array}$ & $\begin{array}{l}\text { Ave. } \\
\log x\end{array}$ & m.e. & $\sigma$ & m.e. \\
\hline STV & $M_{\mathrm{VT}} / L_{T}$ & +2.14 & 0.12 & 0.79 & 0.08 & TG & $M_{\mathrm{VT}} / L_{T}$ & +1.90 & 0.16 & 0.68 & 0.11 \\
\hline A & $\begin{array}{l}M^{\prime} \text { (pe) } \\
M^{\prime}(\mathrm{m}) \\
M^{\prime} \text { (v) } \\
M^{\prime}(\text { pemv) } \\
M_{\mathrm{vT}} / L_{T}\end{array}$ & $\begin{array}{l}-0.05 \\
+0.01 \\
+0.02 \\
-0.01 \\
-0.08\end{array}$ & $\begin{array}{l}0.06 \\
0.02 \\
0.01 \\
0.06 \\
0.12\end{array}$ & $\begin{array}{l}0.36 \\
0.16 \\
0.10 \\
0.41 \\
0.81\end{array}$ & $\begin{array}{l}0.04 \\
0.02 \\
0.02 \\
0.04 \\
0.09\end{array}$ & D & $\begin{array}{l}M^{\prime} \text { (pe) } \\
M^{\prime}(\mathrm{m}) \\
M^{\prime} \text { (v) } \\
M^{\prime} \text { (pemv) } \\
M_{\mathrm{VT}} / L_{T}\end{array}$ & $\begin{array}{r}-0.02 \\
0.00 \\
+0.01 \\
-0.01 \\
-0.05\end{array}$ & $\begin{array}{l}0.08 \\
0.04 \\
0.02 \\
0.09 \\
0.15\end{array}$ & $\begin{array}{l}0.35 \\
0.16 \\
0.10 \\
0.39 \\
0.65\end{array}$ & $\begin{array}{l}0.06 \\
0.03 \\
0.02 \\
0.06 \\
0.11\end{array}$ \\
\hline B & $\begin{array}{l}M^{\prime}(\mathrm{pe}) \\
M^{\prime}(\mathrm{m}) \\
M^{\prime}(\mathrm{v}) \\
M^{\prime}(\text { pemv) } \\
M_{\mathrm{VT}} / L_{T}\end{array}$ & $\begin{array}{r}-0.04 \\
-0.01 \\
0.00 \\
-0.05 \\
+0.03\end{array}$ & $\begin{array}{l}0.05 \\
0.02 \\
0.01 \\
0.05 \\
0.12\end{array}$ & $\begin{array}{l}0.34 \\
0.14 \\
0.10 \\
0.34 \\
0.81\end{array}$ & $\begin{array}{l}0.04 \\
0.02 \\
0.02 \\
0.04 \\
0.09\end{array}$ & $\mathrm{E}$ & $\begin{array}{l}M^{\prime}(\mathrm{pe}) \\
M^{\prime}(\mathrm{m}) \\
M^{\prime}(\mathrm{v}) \\
M^{\prime}(\mathrm{pemv}) \\
M_{\mathrm{VT}} / L_{T}\end{array}$ & $\begin{array}{l}-0.10 \\
-0.01 \\
+0.04 \\
-0.06 \\
-0.12\end{array}$ & $\begin{array}{l}0.08 \\
0.05 \\
0.02 \\
0.08 \\
0.14\end{array}$ & $\begin{array}{l}0.33 \\
0.20 \\
0.10 \\
0.35 \\
0.59\end{array}$ & $\begin{array}{l}0.06 \\
0.03 \\
0.02 \\
0.06 \\
0.10\end{array}$ \\
\hline $\mathrm{C}$ & $\begin{array}{l}M^{\prime} \text { (pe) } \\
M^{\prime}(\mathrm{m}) \\
M^{\prime} \text { (v) } \\
M^{\prime} \text { (pemv) } \\
M_{\mathrm{vT}} / L_{T}\end{array}$ & $\begin{array}{r}-0.08 \\
-0.01 \\
0.00 \\
-0.09 \\
-0.05\end{array}$ & $\begin{array}{l}0.06 \\
0.02 \\
0.01 \\
0.06 \\
0.12\end{array}$ & $\begin{array}{l}0.38 \\
0.12 \\
0.10 \\
0.38 \\
0.81\end{array}$ & $\begin{array}{l}0.04 \\
0.01 \\
0.02 \\
0.04 \\
0.09\end{array}$ & $\mathbf{F}$ & $\begin{array}{l}M^{\prime}(\mathrm{pe}) \\
M^{\prime}(\mathrm{m}) \\
M^{\prime}(\mathrm{v}) \\
M^{\prime}(\mathrm{pemv}) \\
M_{\mathrm{VT}} / L_{T}\end{array}$ & $\begin{array}{l}-0.11 \\
-0.08 \\
-0.02 \\
-0.20 \\
-0.32\end{array}$ & $\begin{array}{l}0.09 \\
0.04 \\
0.02 \\
0.10 \\
0.14\end{array}$ & $\begin{array}{l}0.37 \\
0.15 \\
0.10 \\
0.41 \\
0.59\end{array}$ & $\begin{array}{l}0.06 \\
0.02 \\
0.02 \\
0.07 \\
0.10\end{array}$ \\
\hline STV & $V$ & +2.43 & 0.05 & 0.34 & 0.04 & TG & $V$ & +2.44 & 0.07 & 0.31 & 0.05 \\
\hline A & $\begin{array}{l}V(\mathrm{pe}) \\
V(\mathrm{~m}) \\
V(\mathrm{v}) \\
V(\mathrm{pemv}) \\
V\end{array}$ & $\begin{array}{l}-0.02 \\
+0.02 \\
+0.01 \\
+0.01 \\
-0.02\end{array}$ & $\begin{array}{l}0.02 \\
0.01 \\
0.01 \\
0.02 \\
0.05\end{array}$ & $\begin{array}{l}0.13 \\
0.06 \\
0.05 \\
0.15 \\
0.34\end{array}$ & $\begin{array}{l}0.01 \\
0.01 \\
0.01 \\
0.02 \\
0.04\end{array}$ & D & $\begin{array}{l}V(\mathrm{pe}) \\
V(\mathrm{~m}) \\
V(\mathrm{v}) \\
V \text { (pemv) } \\
V\end{array}$ & $\begin{array}{l}+0.00 \\
+0.02 \\
+0.01 \\
+0.02 \\
+0.05\end{array}$ & $\begin{array}{l}0.03 \\
0.01 \\
0.01 \\
0.03 \\
0.08\end{array}$ & $\begin{array}{l}0.12 \\
0.06 \\
0.05 \\
0.14 \\
0.36\end{array}$ & $\begin{array}{l}0.02 \\
0.01 \\
0.01 \\
0.02 \\
0.06\end{array}$ \\
\hline B & $\begin{array}{l}V \text { (pe) } \\
V \text { (m) } \\
V \text { (v) } \\
V \text { (pemv) } \\
V\end{array}$ & $\begin{array}{r}-0.03 \\
+0.02 \\
0.00 \\
-0.01 \\
+0.03\end{array}$ & $\begin{array}{l}0.02 \\
0.01 \\
0.01 \\
0.02 \\
0.05\end{array}$ & $\begin{array}{l}0.14 \\
0.06 \\
0.05 \\
0.15 \\
0.31\end{array}$ & $\begin{array}{l}0.02 \\
0.01 \\
0.01 \\
0.02 \\
0.03\end{array}$ & $\mathbf{E}$ & $\begin{array}{l}V \text { (pe) } \\
V \text { (m) } \\
V \text { (v) } \\
V \text { (pemv) } \\
V\end{array}$ & $\begin{array}{l}-0.06 \\
+0.03 \\
+0.02 \\
-0.01 \\
-0.03\end{array}$ & $\begin{array}{l}0.03 \\
0.01 \\
0.01 \\
0.03 \\
0.07\end{array}$ & $\begin{array}{l}0.14 \\
0.06 \\
0.05 \\
0.14 \\
0.30\end{array}$ & $\begin{array}{l}0.02 \\
0.01 \\
0.01 \\
0.02 \\
0.05\end{array}$ \\
\hline $\mathrm{C}$ & $\begin{array}{l}V(\mathrm{pe}) \\
V(\mathrm{~m}) \\
V(\mathrm{v}) \\
V(\mathrm{pemv}) \\
V\end{array}$ & $\begin{array}{r}-0.01 \\
-0.01 \\
0.00 \\
-0.02 \\
-0.03\end{array}$ & $\begin{array}{l}0.02 \\
0.01 \\
0.01 \\
0.02 \\
0.06\end{array}$ & $\begin{array}{l}0.12 \\
0.05 \\
0.05 \\
0.15 \\
0.39\end{array}$ & $\begin{array}{l}0.01 \\
0.01 \\
0.01 \\
0.02 \\
0.04\end{array}$ & $\mathbf{F}$ & $\begin{array}{l}V \text { (pe) } \\
V \text { (m) } \\
V \text { (v) } \\
V \text { (pemv) } \\
V\end{array}$ & $\begin{array}{l}-0.02 \\
-0.01 \\
-0.01 \\
-0.03 \\
-0.03\end{array}$ & $\begin{array}{l}0.03 \\
0.01 \\
0.01 \\
0.03 \\
0.07\end{array}$ & $\begin{array}{l}0.13 \\
0.04 \\
0.05 \\
0.14 \\
0.30\end{array}$ & $\begin{array}{l}0.02 \\
0.01 \\
0.01 \\
0.02 \\
0.05\end{array}$ \\
\hline STV & $R$ & +0.38 & 0.07 & 0.43 & 0.05 & TG & $R$ & +0.10 & 0.10 & 0.42 & 0.07 \\
\hline A & $\begin{array}{l}R(\mathrm{pe}) \\
R(\mathrm{~m}) \\
R(\mathrm{v}) \\
R(\mathrm{pemv}) \\
R\end{array}$ & $\begin{array}{r}+0.02 \\
-0.03 \\
0.00 \\
-0.02 \\
-0.02\end{array}$ & $\begin{array}{l}0.03 \\
0.02 \\
0.00 \\
0.04 \\
0.06\end{array}$ & $\begin{array}{l}0.17 \\
0.14 \\
0.00 \\
0.23 \\
0.39\end{array}$ & $\begin{array}{l}0.02 \\
0.02 \\
0.00 \\
0.02 \\
0.04\end{array}$ & D & $\begin{array}{l}R \text { (pe) } \\
R(\mathrm{~m}) \\
R \text { (v) } \\
R \text { (pemv) } \\
R\end{array}$ & $\begin{array}{r}+0.01 \\
-0.03 \\
0.00 \\
-0.02 \\
-0.05\end{array}$ & $\begin{array}{l}0.03 \\
0.02 \\
0.00 \\
0.04 \\
0.08\end{array}$ & $\begin{array}{l}0.14 \\
0.10 \\
0.00 \\
0.15 \\
0.36\end{array}$ & $\begin{array}{l}0.02 \\
0.02 \\
0.00 \\
0.03 \\
0.06\end{array}$ \\
\hline B & $\begin{array}{l}R(\mathrm{pe}) \\
R(\mathrm{~m}) \\
R \text { (v) } \\
R \text { (pemv) } \\
R\end{array}$ & $\begin{array}{r}+0.07 \\
-0.05 \\
0.00 \\
+0.02 \\
+0.06\end{array}$ & $\begin{array}{l}0.01 \\
0.02 \\
0.00 \\
0.03 \\
0.06\end{array}$ & $\begin{array}{l}0.06 \\
0.16 \\
0.00 \\
0.18 \\
0.41\end{array}$ & $\begin{array}{l}0.01 \\
0.02 \\
0.00 \\
0.02 \\
0.04\end{array}$ & $\mathbf{E}$ & $\begin{array}{l}R(\mathrm{pe}) \\
R(\mathrm{~m}) \\
R(\mathrm{v}) \\
R \text { (pemv) } \\
R\end{array}$ & $\begin{array}{r}+0.06 \\
-0.07 \\
0.00 \\
-0.01 \\
-0.03\end{array}$ & $\begin{array}{l}0.03 \\
0.03 \\
0.00 \\
0.04 \\
0.09\end{array}$ & $\begin{array}{l}0.13 \\
0.14 \\
0.00 \\
0.19 \\
0.39\end{array}$ & $\begin{array}{l}0.02 \\
0.02 \\
0.00 \\
0.03 \\
0.07\end{array}$ \\
\hline C & $\begin{array}{l}R(\mathrm{pe}) \\
R(\mathrm{~m}) \\
R(\mathrm{v}) \\
R \text { (pemv) } \\
R\end{array}$ & $\begin{array}{r}0.00 \\
0.00 \\
0.00 \\
0.00 \\
-0.06\end{array}$ & $\begin{array}{l}0.02 \\
0.02 \\
0.00 \\
0.03 \\
0.07\end{array}$ & $\begin{array}{l}0.14 \\
0.12 \\
0.00 \\
0.18 \\
0.46\end{array}$ & $\begin{array}{l}0.02 \\
0.01 \\
0.00 \\
0.02 \\
0.05\end{array}$ & $\mathbf{F}$ & $\begin{array}{l}R(\mathrm{pe}) \\
R(\mathrm{~m}) \\
R(\mathrm{v}) \\
R \text { (pemv) } \\
R\end{array}$ & $\begin{array}{r}-0.04 \\
-0.07 \\
0.00 \\
-0.11 \\
-0.09\end{array}$ & $\begin{array}{l}0.06 \\
0.03 \\
0.00 \\
0.08 \\
0.09\end{array}$ & $\begin{array}{l}0.24 \\
0.14 \\
0.00 \\
0.32 \\
0.36\end{array}$ & $\begin{array}{l}0.04 \\
0.02 \\
0.00 \\
0.05 \\
0.06\end{array}$ \\
\hline
\end{tabular}

* Sample size $=44 . \quad \dagger$ Sample size $=19$.

NOTES.- $M^{\prime}(\mathrm{pe})=M(\mathrm{pe}) / M, M^{\prime}(\mathrm{v})=M_{\mathrm{VT}} / L_{T}(\mathrm{v})$, etc. $\sigma=$ Standard deviation of $\log x$ about $\langle\log x\rangle$. m.e. $=$ Mean error of ave. or $\sigma$.

it appears that the intrinsic mass-to-light ratio of STV and TG groups is correlated with intrinsic virial velocity dispersion. The situation regarding plots of $M_{\mathrm{VT}} / L_{T}$ versus $R$ is unclear. The STV groups show a significant correlation but the TG groups do not. This discordance may reflect the small sample of TG groups and/or the difficulty regarding the definition of groups discussed in § III $a$.

\section{d) Synthesized Groups}

For rich clusters of galaxies, it is relatively straightforward to derive structural and dynamical properties such as $(a)$ the frequency distribution of the absolute value of galactic radial velocity relative to the center of mass, $v_{p} ;(b)$ the dependence of the surface density of galaxies, $S$, upon projected radius from the center of mass, $r_{p} ;(c)$ the dependence of $v_{p}$ on $r_{p} ;(d)$ the dependence of galactic mass on $v_{p}$; and (e) the dependence of galactic mass on $r_{p}$. Similar plots for groups generally contain little statistically significant information because of their small populations. However, we found in $\S$ III $b$ that the STV and TG groups have crossing times smaller than $H^{-1}$, which suggests that they are bound, so that it seems reasonable to 
TABLE 6

Regression-Line Coefficients and Correlation Coefficient for STV, TG, and Model Group Samples

$\log y=\left(a_{0} \pm S_{0}\right)+\left(a_{1} \pm S_{1}\right) \log x$

\begin{tabular}{|c|c|c|c|c|c|c|c|c|c|c|}
\hline Sample & $a_{1}$ & $S_{1}$ & $a_{0}$ & $S_{0}$ & $r$ & $N$ & $Z_{0}$ & $Z_{1}$ & $\begin{array}{r}P \geq 95 \% \\
\left(z_{1} \geq 1.96\right)\end{array}$ & $\begin{aligned} P & \geq 99 \% \\
\left(z_{1}\right. & \geq 2.58)\end{aligned}$ \\
\hline \multicolumn{11}{|c|}{$y=M_{\mathrm{VT}} / L_{T}, x=V$} \\
\hline 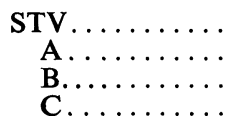 & $\begin{array}{l}+1.70 \\
+1.10 \\
+0.23 \\
+0.18\end{array}$ & $\begin{array}{l}0.24 \\
0.33 \\
0.40 \\
0.32\end{array}$ & $\begin{array}{l}-1.99 \\
-0.05 \\
+0.02 \\
-0.04\end{array}$ & $\begin{array}{l}0.60 \\
0.11 \\
0.12 \\
0.12\end{array}$ & $\begin{array}{l}+0.73 \\
+0.46 \\
+0.09 \\
+0.09\end{array}$ & $\begin{array}{l}44 \\
44 \\
44 \\
44\end{array}$ & $\begin{array}{l}+5.95 \\
+3.18 \\
+0.58 \\
+0.58\end{array}$ & $\begin{array}{r}+2.76 \\
+5.37 \\
+5.37\end{array}$ & $\begin{array}{l}\times \\
\times \\
\times\end{array}$ & $\begin{array}{l}x \\
x \\
x\end{array}$ \\
\hline 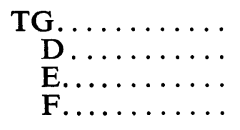 & $\begin{array}{l}+1.61 \\
+0.72 \\
-0.22 \\
+0.84\end{array}$ & $\begin{array}{l}0.36 \\
0.40 \\
0.47 \\
0.43\end{array}$ & $\begin{array}{l}-2.03 \\
-0.09 \\
-0.13 \\
-0.30\end{array}$ & $\begin{array}{l}0.88 \\
0.14 \\
0.14 \\
0.13\end{array}$ & $\begin{array}{l}+0.74 \\
+0.40 \\
-0.11 \\
+0.43\end{array}$ & $\begin{array}{l}19 \\
19 \\
19 \\
19\end{array}$ & $\begin{array}{l}+3.80 \\
+1.69 \\
-0.44 \\
+1.84\end{array}$ & $\begin{array}{l}+2.11 \\
+4.24 \\
+1.96\end{array}$ & $\begin{array}{l}\times \\
\times \\
\times\end{array}$ & $x$ \\
\hline \multicolumn{11}{|c|}{$y=M_{\mathrm{VT}} / L_{T}, x=R$} \\
\hline 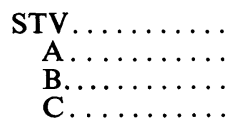 & $\begin{array}{l}+1.30 \\
+0.72 \\
+0.06 \\
+0.49\end{array}$ & $\begin{array}{l}0.20 \\
0.30 \\
0.30 \\
0.26\end{array}$ & $\begin{array}{l}+1.65 \\
-0.07 \\
+0.02 \\
-0.02\end{array}$ & $\begin{array}{l}0.11 \\
0.12 \\
0.12 \\
0.12\end{array}$ & $\begin{array}{l}+0.71 \\
+0.35 \\
+0.03 \\
+0.27\end{array}$ & $\begin{array}{l}44 \\
44 \\
44 \\
44\end{array}$ & $\begin{array}{l}+5.68 \\
+2.34 \\
+0.19 \\
+1.77\end{array}$ & $\begin{array}{r}+3.34 \\
+5.49 \\
+3.91\end{array}$ & $\begin{array}{l}\times \\
\times \\
\times\end{array}$ & $\begin{array}{l}x \\
\times \\
x\end{array}$ \\
\hline 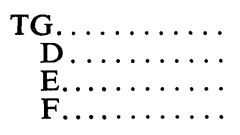 & $\begin{array}{l}+0.76 \\
+0.02 \\
+0.72 \\
+0.12\end{array}$ & $\begin{array}{l}0.35 \\
0.45 \\
0.32 \\
0.39\end{array}$ & $\begin{array}{l}+1.83 \\
-0.05 \\
-0.10 \\
-0.31\end{array}$ & $\begin{array}{l}0.15 \\
0.16 \\
0.12 \\
0.14\end{array}$ & $\begin{array}{l}+0.46 \\
+0.01 \\
+0.48 \\
+0.07\end{array}$ & $\begin{array}{l}19 \\
19 \\
19 \\
19\end{array}$ & $\begin{array}{l}+1.99 \\
+0.04 \\
+2.09 \\
+0.28\end{array}$ & $\begin{array}{l}+1.95 \\
-0.10 \\
+1.71\end{array}$ & & \\
\hline \multicolumn{11}{|c|}{$y=V, x=R$} \\
\hline 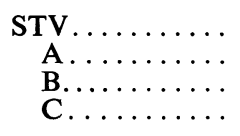 & $\begin{array}{l}+0.20 \\
+0.05 \\
+0.07 \\
+0.06\end{array}$ & $\begin{array}{l}0.12 \\
0.13 \\
0.12 \\
0.13\end{array}$ & $\begin{array}{l}+2.36 \\
-0.02 \\
+0.02 \\
-0.03\end{array}$ & $\begin{array}{l}0.07 \\
0.05 \\
0.05 \\
0.06\end{array}$ & $\begin{array}{l}+0.25 \\
+0.05 \\
+0.10 \\
+0.07\end{array}$ & $\begin{array}{l}44 \\
44 \\
44 \\
44\end{array}$ & $\begin{array}{l}+1.64 \\
+0.32 \\
+0.64 \\
+0.45\end{array}$ & $\begin{array}{l}+1.32 \\
+0.99 \\
+1.19\end{array}$ & & \\
\hline 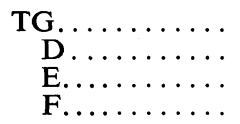 & $\begin{array}{l}+0.11 \\
+0.04 \\
+0.02 \\
+0.09\end{array}$ & $\begin{array}{l}0.18 \\
0.25 \\
0.19 \\
0.20\end{array}$ & $\begin{array}{l}+2.43 \\
+0.05 \\
-0.03 \\
-0.02\end{array}$ & $\begin{array}{l}0.08 \\
0.09 \\
0.07 \\
0.07\end{array}$ & $\begin{array}{l}+0.14 \\
+0.04 \\
+0.02 \\
+0.11\end{array}$ & $\begin{array}{l}19 \\
19 \\
19 \\
19\end{array}$ & $\begin{array}{l}+0.56 \\
+0.16 \\
+0.08 \\
+0.44\end{array}$ & $\begin{array}{l}+0.40 \\
+0.48 \\
+0.12\end{array}$ & & \\
\hline
\end{tabular}

Notes. $-r=$ correlation coefficient, $N=$ number in sample, $Z_{0}=Z$-statistic (Hogg and Craig 1970; Freund 1971) for testing if observed $r$ could come from a population with $r=0 . Z_{1}=Z$-statistic for testing if the $r$ of the STV or TG sample could come from a population with the $r$ of the model sample. If $Z_{1} \geq 1.96$, this hypothesis can be rejected with $\geq 95 \%$ confidence. If $Z_{1} \geq 2.58$, the hypothesis can be rejected with $\geq 99 \%$ confidence.

superpose the individual STV groups (or the TG groups) to obtain a populous "synthesized group" for which properties $(a)-(e)$ can be derived to represent the weighted average properties of groups. We found in $\S$ III $b$, however, that groups have a range in velocity dispersion and radius. To take this into account, we will normalize $v_{p}$ for each galaxy by dividing it by the average velocity for its group, $\left\langle v_{p}\right\rangle$, and similarly $r_{p}$ will be normalized by $\left\langle r_{p}\right\rangle$.

We have created one synthesized group from the 63 STV groups and another from the 29 TG groups. We have performed the following investigations on these data: (a) Frequency distributions of the normalized absolute radial velocities, $v_{p} \mid\left\langle v_{p}\right\rangle$, of these synthesized groups are presented in Figure 9. The hypothesis that the observed frequency distributions are random samplings of a Gaussian velocity distribution with the observed normalized velocity dispersion cannot be ruled out on the $50 \%$ significance level of a chi-square test. This agrees with the result of Yahil and Vidal (1977) that clusters in general have frequency distributions of their observed radial velocities which are consistent with an underlying
Gaussian distribution law. Each observed Gaussian velocity distribution is the convolution of the true distribution and a much narrower distribution of velocity measurement errors. Thus, $\sigma_{\mathrm{v}}($ true $)=$ $0.96 \sigma_{\mathrm{v}}$ (observed) for the STV sample, and $\sigma_{\mathrm{v}}($ true $)=$ $0.88 \sigma_{\mathrm{v}}$ (observed) for the TG sample, and the true distributions are also approximately Gaussian, perhaps slightly truncated. $(b)$ The radial dependence of the surface density of galaxies for the synthesized groups is presented in Figure 10. From $r_{p}=0$ to $r_{p} \approx\left\langle r_{p}\right\rangle$, the surface density is approximately constant; the sharp drop-off of surface density at large radial distances could be an artificial consequence of the group identification procedures. ${ }^{2}$ The approximately constant surface-density distribution in the main body of a group is different from that for a rich regular cluster, which is well represented by a projected isothermal sphere (Zwicky 1957; Bahcall $1972 a, b, 1973 a, b, 1974,1975)$. (c) Applying elementary dynamical considerations to the observed surface density distribution, we expect $v_{p}$ to increase

\footnotetext{
${ }^{2}$ This was pointed out to us by an anonymous referee.
} 

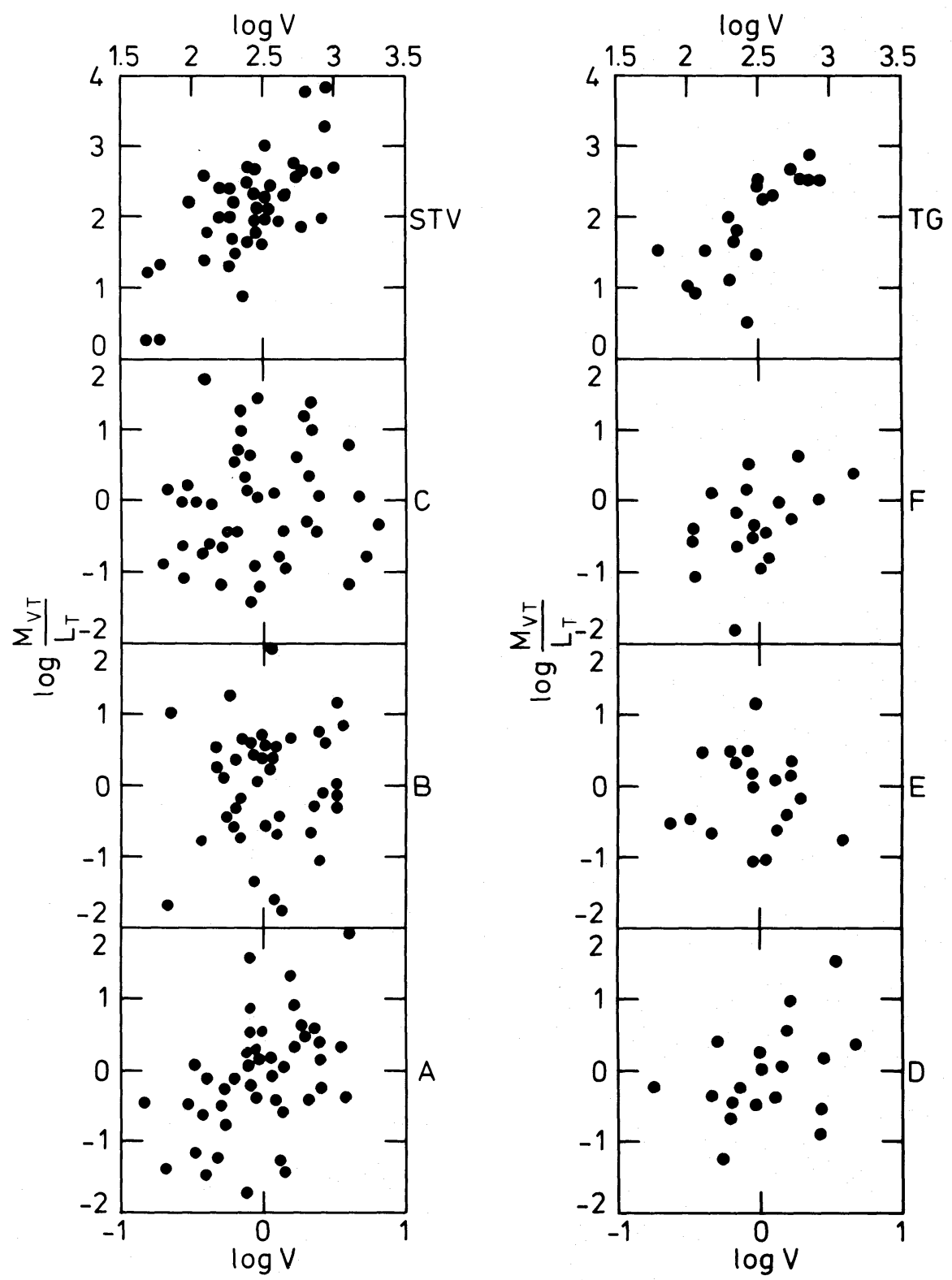

FIG. 8.- Logarithm of the virial mass-to-light ratio versus logarithm of the virial velocity dispersion for (a) STV groups, set A, set $\mathrm{B}$, and set $\mathrm{C}$ model groups, and $(b)$ TG groups, set $\mathrm{D}$, set $\mathrm{E}$, and set $\mathrm{F}$ model groups with $\sigma\left(V^{2}\right) / V^{2}<0.5$. Symbols are explained in the legend to Fig. 1 .

with increasing $r_{p}$ for $r_{p} \leq\left\langle r_{p}\right\rangle$. This may in fact be the case (Fig. 11), but the uncertainties in the diagram of $v_{p}$ versus $r_{p}$ are very large. $(d, e) \mathrm{We}$ also find that the masses of galaxies in the synthesized groups tend to increase with decreasing $v_{p}$ and $r_{p}$, but this result may not be physically significant because the velocities and radial distances are defined relative to the center of mass of each individual group, which is determined from data of only a small number of galaxies, with the most massive often dominating.

\section{DISCUSSION OF THE LITERATURE}

Some of the results obtained in our study are at variance with conclusions reached in the literature, which have greatly influenced the thinking of many astronomers interested in dynamical properties of groups. For these reasons, a brief discussion of pertinent parts of the literature is warranted.

Materne and Tammann (1974) derived ratios of virial mass to luminous mass for the first 14 groups 

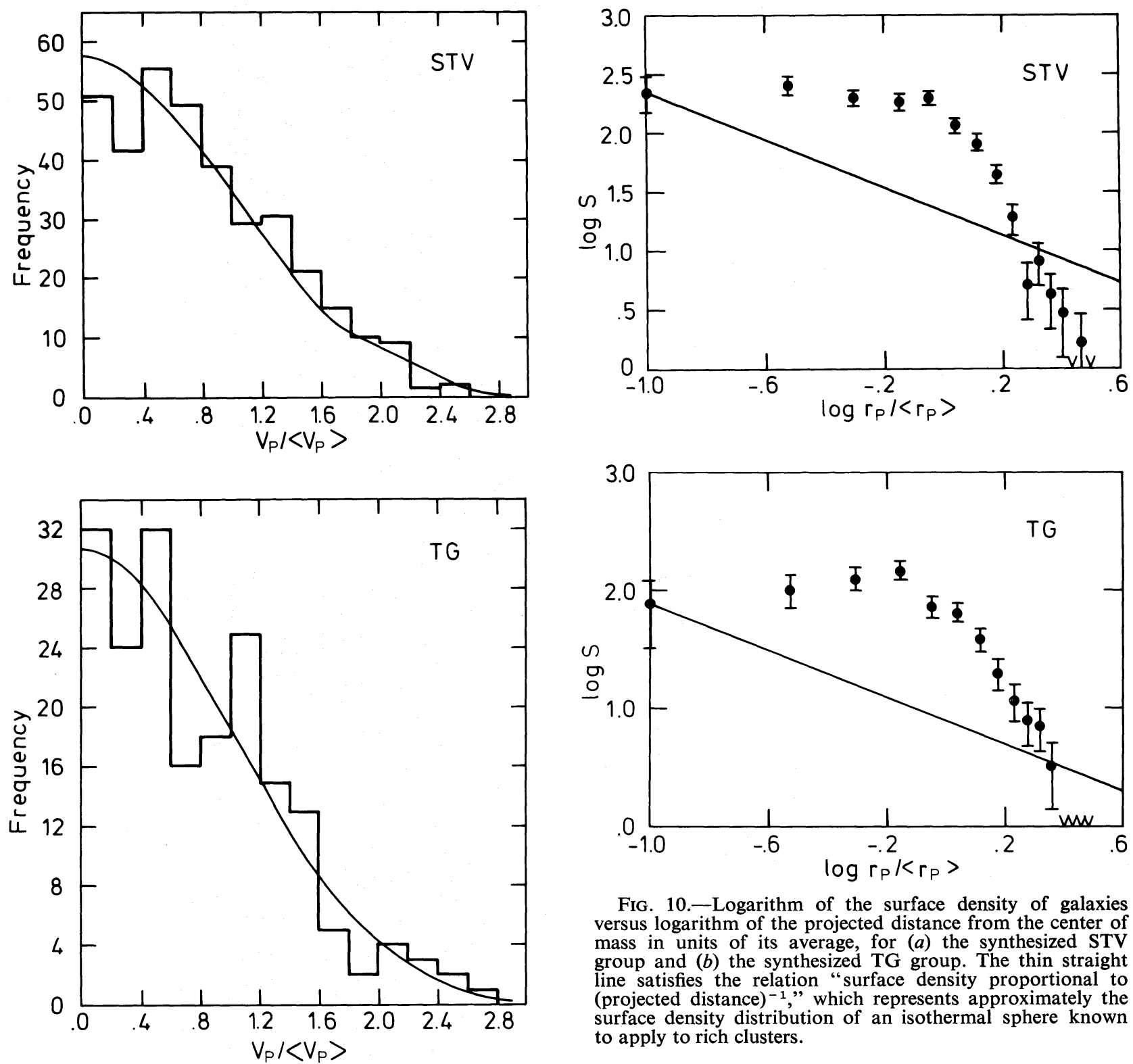

FIG. 10.-Logarithm of the surface density of galaxies versus logarithm of the projected distance from the center of mass in units of its average, for $(a)$ the synthesized STV group and $(b)$ the synthesized TG group. The thin straight line satisfies the relation "surface density proportional to (projected distance) ${ }^{-1}$," which represents approximately the surface density distribution of an isothermal sphere known to apply to rich clusters.

FIG. 9.-Frequency distribution of the absolute value of galactic radial velocity relative to the center of mass in units of its average, for (a) synthesized STV group and $(b)$ synthesized TG group. The thin line is a Gaussian distribution with a dispersion equal to that of the observed distribution.

listed in Table 1 of the present study. There is basic agreement between their values and the mass-to-light ratios derived in the present paper. Materne and Tammann (1974) emphasize that observational errors make it necessary to exercise great caution when testing for correlations between virial parameters. We have attempted to heed their warning.

Tully and Fisher (1975) obtained extensive measurements of radial velocities for the members of groups $\operatorname{deV} 6,12$, and 51. After redefining these groups, they

derived ratios of virial mass to luminous mass $\left(M_{L}=\right.$ luminosity multiplied by an assumed average massto-light ratio of group members), and concluded that very large amounts of hidden mass are not required. We cannot agree with that conclusion, because the virial mass-to-light ratios of their redefined groups are all approximately 200 solar units. We note that the mass-to-light ratio for deV 12 derived in the present study agrees with that obtained by Tully and Fisher from a larger sample of member galaxies. Further, deV 6 was divided by Tully and Fisher into two subgroups because of a small velocity separation, and they then noticed a separation in morphological types of member galaxies as well. While this may be a valid redefinition of $\operatorname{deV} 6$, it is not beyond doubt. 

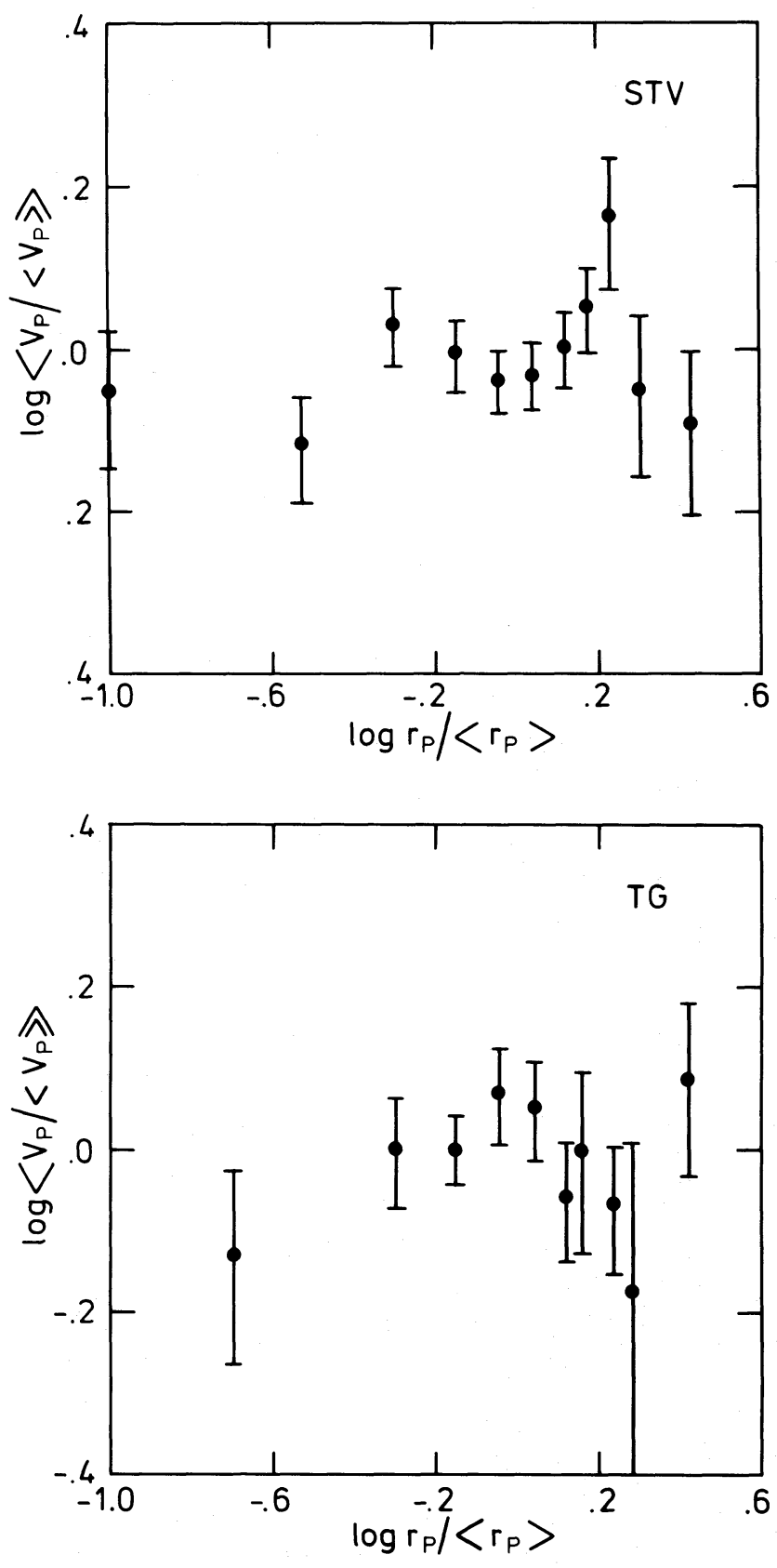

FIG. 11.- Logarithm of the absolute values of the radial velocities of the galaxies relative to the center of mass in units of the average radial velocity versus the logarithm of the projected distances from the center of mass in units of the average distance, for $(a)$ the synthesized STV group and (b) the synthesized TG group.

For example, the Local Group might likewise be redefined as an M31 group and a Milky Way group, but the Local Group is still a group because the members do not appear to participate in the cosmological expansion (Hubble 1936; Humason and Wahlquist 1955). Similarly, the crossing time of deV 6 is about
$0.5 H^{-1}$. For the group deV 51, two galaxies with radial velocities from the literature near $2100 \mathrm{~km} \mathrm{~s}^{-1}$ were rejected as members by Tully and Fisher because the adopted members have velocities between 1300 and $1800 \mathrm{~km} \mathrm{~s}^{-1}$. One of the rejected galaxies, NGC 6340 , has a recent $21 \mathrm{~cm}$ velocity determination by Balick, Faber, and Gallagher (1976) of $1436 \mathrm{~km} \mathrm{~s}^{-1}$, substantially smaller than the $2146 \mathrm{~km} \mathrm{~s}^{-1}$ cataloged by de Vaucouleurs et al. (1976).

Materne (1974) has demonstrated conclusively that an earlier determination of the virial mass-to-light ratio of deV 7 is spurious because of a spurious radial velocity for NGC 891 . This result has suggested to some astronomers that the large mass-to-light ratios of groups in general may be caused by spurious velocities. We do not believe this to be the case for two reasons: (a) The vast majority of galaxies do not have spurious velocities (e.g., see Dickel and Rood 1978). (b) The virial mass-to-light ratio and crossing time derived by the statistical virial theorem of Geller and Peebles (1973), which automatically frees itself of spurious velocities, agree well with the median values for individual groups found in the present study.

The two peaks in the histogram of virial crossing times, $t_{\mathrm{VT}}=R / V$, derived from early data for the groups listed by de Vaucouleurs (1975) were interpreted by Gott et al. (1974) and Turner and Sargent (1974) to represent two kinds of groups: (a) bound groups, and $(b)$ unbound density enhancements of nearest neighbors separating from one another in the Hubble flow. The possible existence of this type of group was first suggested by Gott, Wrixon, and Wannier (1973). The modern data used in the present study show that the histogram of virial crossing times is single-peaked. Moreover, the crossing times $t_{c}=$ $\langle r\rangle \mid\langle v\rangle$ for all but one of the observed groups are less than $H^{-1}$, indicating that they are bound. Turner and Sargent (1974) conclude that about $70 \%$ of the groups statistically detected by the analysis of Geller and Peebles (1973) are unbound density enhancements, but we have shown that the average crossing time of these groups is about $0.2 H^{-1}$, which indicates that they are bound.

Finally, we point out that the claim by Turner and Sargent (1974) that the virial correlations are "artificially generated by the method of analysis" comes from an argument which is essentially a restatement of the virial correlations in a different form, i.e., although $M$ and $L_{T}$ of individual galaxies are proportional, the values of $M_{\mathrm{VT}}$ and $L_{T}$ for groups are not related to $V$ and possibly $R$ in the same manner.

\section{CONCLUSIONS}

By applying the virial relations derived by Materne (1974) to modern observational data, we have derived a median mass-to-light ratio of $\mathbf{4 0}$ solar units for the TG groups and 120 solar units for the STV groups. The discordance appears to be caused by uncertainties in sampling and by difficulties in defining a group. The problem is whether a large aggregate or only each of its component units is a bound group. Perhaps 
both are bound groups. The solar system is a bound group but so is Jupiter's satellite system. White (1976) found that a computer-simulated initially expanding bound $N$-body cluster continually develops subcondensations which continually amalgamate as the cluster evolves. If all of the TG and STV are in fact bound, then, because the STV groups are statistically larger than the TG groups, the discordance in $M_{\mathrm{VT}} / L_{T}$ could mean that this parameter increases with virial radius. It should be emphasized that the values of mass-to-light ratios obtained in the present study do not differ significantly from those of many other workers (e.g., Gott and Turner 1977) when the differences in adopted absorption (internal and external) corrections, type of magnitude, Hubble constant, etc., are taken into account.

Virial mass-to-light ratios $\sim 40-120$ for groups compare with values $\sim 10$ for individual galaxies derived from their internal motions. The factor of 4-12 difference, while significant, is smaller than previous estimates by a factor of about 6 because of the following contributions: The group $M_{\mathrm{VT}} / L_{T}$ estimates tend to be about a factor of 2 smaller than previous values because they are corrected for uncertainties in radial-velocity measurements and are derived from better data. The mass-to-light ratios of individual spiral and irregular galaxies are a factor of 3 larger than previous values because the rotation curves are flatter and the radii of maximum rotational velocity are larger than assumed previously.

The groups are believed to be gravitationally bound, not only because their crossing times are smaller than $H^{-1}$, but also because the composite frequency distribution of their radial velocities is a Gaussian. The alternative, that the groups are violently expanding and the expansions began typically $2-4$ billion years ago, is not viable for two reasons: (a) The colormagnitude diagrams of star clusters within galaxies in the Local Group indicate that they are older than $10^{10}$ years, and galaxies in other groups are morphologically similar to the Local Group galaxies. (b) Sandage and Tammann (1975) have derived distances to individual galaxies in nearby groups from measurements of their luminosity class and $\mathrm{H}$ II region diameters. A plot of the individual distances relative to the group average versus the radial velocities relative to the group average for these galaxies does not reveal a significant correlation as would be expected for groups expanding from their own centers.

An attempt has been made in this study to assess the contribution by projection and quasi-equilibrium effects, uncertainties in radial velocities, and uncertainties in galactic masses to the observed virial correlations $\left(M_{\mathrm{VT}} / L_{T} \approx V^{1.6}, \quad M_{\mathrm{VT}} / L_{T} \approx R\right)$. Our analysis indicates that these statistical and observational uncertainties cannot account for the correlation of $M_{\mathrm{VT}} / L_{T}$ versus $V$, but the situation is unclear regarding the correlations of $M_{\mathrm{VT}} / L_{T}$ versus $R$. The correlation $M_{\mathrm{VT}} / L_{T} \approx V^{1.6}$ is therefore inferred to be intrinsic (i.e., cosmic), but further caution is warranted. Although we have attempted to adopt realistic uncertainties, it is conceivable that one or more of the uncertainties used were, in fact, severely underestimated. The following improvements are needed: (a) Projection and quasi-equilibrium effects $-N$-body experiments involving a variety of initial conditions, mass spectra, and values of $N$ should be performed to assess the sensitivity of projection and quasi-equilibrium effects on these properties. (b) Radial velocity uncertainties-happily, more extensive radial velocities of high accuracy will soon be forthcoming. They will lead to (i) reliable assessments of difficulties in identifying actual groups and distinguishing members from nonmembers, (ii) large samples of definitive groups with $\sigma\left(V^{2}\right) / V^{2}<0.5$, and (iii) increased populations of known group members. (c) Galactic mass uncertainties-accurate rotation curves to the faintest observable outer regions of a large sample of galaxies are greatly needed. Lacking such data, it would be useful to estimate the sensitivity of the values of the virial parameters to mass errors by adopting a variety of different assumed errors.

If the one or both virial correlations are actually intrinsic, then either (a) the fraction of missing mass in a group, whether in galactic halos or between galaxies, increases with $V$ (and $R$ ?), or $(b)$ the physical laws governing the dynamics of groups of galaxies are different or more general than the laws known to apply in the solar system. Ginzburg $(1975,1976)$ has contributed some interesting remarks concerning this possibility. It is therefore imperative for astronomers to determine unequivocally whether or not statistical and observational uncertainties actually cause the observed virial correlations.

It is a pleasure to thank E. L. Turner for allowing us to use results of his computer $N$-body experiments, and for pointing out the rigorous way to derive the projected center of mass of a group. We are grateful to G. Knapp and to R. B. Tully for providing us with accurate radial velocities of group galaxies without previously known values. This research was supported in part by the National Science Foundation Research grant GP-36167A to Michigan State University. J. R. D. acknowledges a travel award to Leiden by the Netherlands-America Commission for Educational Exchange through the Fulbright-Hays program.

\section{REFERENCES}

Aarseth, S. J., and Saslaw, W. C. 1972, Ap. J., 172, 17.

Abell, G. O. 1975, in Galaxies and the Universe, ed. A. Sandage, M. Sandage, and J. Kristian (Chicago: University of Chicago Press), p. 617.

Allen, C. W. 1955, Astrophysical Quantities (London: Athlone Press), p. 131

Bahcall, N. A. 1972a, A.J., 77, 550.
Bahcall, N. A. $1972 b$, Ap. J., 180, 696.

. 1973a, Ap.J., 183, 783.

1973b, Ap. J., 186, 1179.

1974, Ap. J., 187, 439.

1975, Ap. J., 198, 249.

Balick, B., Faber, S. M., and Gallagher, J. S. 1976, Ap. J., 209, 710. 
Burbidge, E. M., and Sargent, W. L. W. 1971, in Nuclei of Galaxies, ed. D. J. K. O'Connell (New York: American Elsevier), p. 351.

de Vaucouleurs, A., Shobbrook R. R., and Strobel, A. 1976, A.J., 81, 219.

de Vaucouleurs, G. 1975, in Galaxies and the Universe, ed. A. Sandage, M. Sandage, and J. Kristian (Chicago: University of Chicago Press), p. 557.

de Vaucouleurs, G., and de Vaucouleurs, A. 1964, Reference Catalogue of Bright Galaxies (Austin: University of Texas Press) (RC 1).

de Vaucouleurs, G., de Vaucouleurs, A., and Corwin, H. G. 1976, Second Reference Catalogue of Bright Galaxies (Austin: University of Texas Press) (RC 2).

Dickel, J. R., and Rood, H. J. 1978, $A p$. J., in press.

Faber, S. M., Balick, B., Gallagher, J. S., and Knapp, G. R. 1977, Ap. J., 214, 383.

Faber, S. M., and Jackson, R. E. 1976, Ap. J., 204, 668.

Fisher, J. R., and Tully, R. B. 1975, Astr. Ap., 44, 151.

Freund, J. E. 1971, Mathematical Statistics (Englewood Cliffs, NJ: Prentice-Hall).

Geller, M. J., and Peebles, P. J. E. 1973, Ap. J., 184, 329.

Ginzburg, V. L. 1975, Quart. J.R.A.S., 16, 265.

- 1976, Key Problems of Physics and Astrophysics (English transl.) (Moscow: Mir; USA Distributor: Imported Publications, 320 West Ohio St., Chicago, IL), pp. 96-102.

Gott, J. R., Gunn, J. E., Schramm, D. N., and Tinsley, B. M. 1974, Ap. J., 194, 543.

Gott, J. R., and Turner, E. L. 1977, Ap. J., 213, 209.

Gott, J. R., Wrixon, G. T., and Wannier, P. 1973, Ap. J., 186, 777.

Hogg, R. V., and Craig, A. T. 1970, Introduction to Mathematical Statistics (New York: Macmillan).

Holmberg, E. B. 1958, Medd. Lund, Ser. 2, No. 136

. 1974, Astr. Ap., 35, 121.

Hubble, E. 1936, The Realm of the Nebulae (New Haven: Yale University Press), p. 151.

Huchtmeier, W. K. 1975, Astr. Ap., 45, 259.

Huchtmeier, W. K., Tammann, G. A., and Wendker, H. J. 1976, Astr. Ap., 46, 381.

Humason, M. L., and Wahlquist, H. D. 1955, A.J., 60, 254.

Jackson, J. C. 1975, M.N.R.A.S., 173, 41 p.
Karachentsev, I. D. 1966, Astrofizika, 2, 81 (English transl. 1967, Astrophysics, 2, 39)

Kirshner, R. P. 1977, Ap. J., 212, 319.

Lewis, B. M., and Robinson, B. J. 1973, Astr. Ap., 23, 295.

Limber, D. N. 1961, in Problems of Extragalactic Research, ed. G. C. McVittie (New York: Macmillan), p. 239.

Martin, W. L. 1976, M.N.R.A.S., 175, 633.

Materne, J. 1974, Astr. Ap., 33, 451.

Materne, J., and Tammann, G. A. 1974, Astr. Ap., 37, 383.

Morton, D. C., and Chevalier, R. A. 1972, Ap. J., 174, 489.

. 1973, Ap. J., 179, 55.

Neyman, J., Page, T., and Scott, E. L. 1961, A.J., 66, 533-636.

Nilson, P. 1973, Uppsala General Catalogue of Galaxies (Uppsala: Uppsala Offset Center AB) (UGC).

Rood, H. J., and Dickel, J. R. 1976, Ap. J., 205, 346.

Rood, H. J., Rothman, V. C. A., and Turnrose, B. E. 1970, Ap. J., 162, 411.

Sandage, A. 1975, Ap. J., 202, 563.

Sandage, A., and Tammann, G. A. 1975, Ap. J., 196, 313

Sargent, W. L. W., Schechter, P. L., Boksenberg, A., and Shortridge, K. 1977, Ap. J., 212, 326.

Schechter, P. 1976, Ap. J., 203, 297.

Shapley, H., and Ames, A. 1932, Annals Harvard College Obs., 88, No. 2.

Shostak, G. S. 1975, Ap. J., 198, 527.

Turner, E. L., and Gott, J. R. 1976a, Ap. J. Suppl., 32, 409.

- 1976b, Ap. J., 209, 6.

Turner, E. L., and Sargent, W. L. W. 1974, Ap. J., 194, 587.

Tully, R. B., and Fisher, J. R. 1975, paper presented at the third European Regional Meeting of the IAU in Tiflis, USSR.

White, S. D. M. 1976, M.N.R.A.S., 177, 717.

Williams, T. B. 1977, Ap. J., 214, 685.

Wilson, C. P. 1975, in IAU Symposium No. 69, Dynamics of Stellar Systems, ed. A. Hayli (Dordrecht: Reidel), p. 207.

Yahil, A., and Vidal, N. V. 1977, Ap. J., 214, 347.

Zwicky, F. 1957, Morphological Astronomy (Berlin: SpringerVerlag), pp. 134-144.

Zwicky, F., Herzog, E., Karpowicz, M., Kowal, C. T., and Wild, P. 1960-1968, Catalogue of Galaxies and of Clusters of Galaxies, Vol. 1-6 (Pasadena: California Institute of Technology).

JoHN R. Dickel: Sterrewacht te Leiden, Huygens Laboratorium, Wassenaarseweg 78, Leiden, The Netherlands Herbert J. Rood: 52 Elizabeth Street, South Bound Brook, NJ 08880 